\title{
Partial rescue of V1V2 mutant infectivity by HIV-1 cell-cell transmission supports the domain's exceptional capacity for sequence variation
}

Oliver F Brandenberg ${ }^{1}$, Peter Rusert ${ }^{1}$, Carsten Magnus ${ }^{1}$, Jacqueline Weber ${ }^{1}$, Jürg Böni ${ }^{1}$, Huldrych F Günthard ${ }^{2}$, Roland R Regoes ${ }^{3}$ and Alexandra Trkola ${ }^{1 *}$

\begin{abstract}
Background: Variable loops 1 and 2 (V1V2) of the HIV-1 envelope glycoprotein gp120 perform two key functions: ensuring envelope trimer entry competence and shielding against neutralizing antibodies. While preserving entry functionality would suggest a high need for V1V2 sequence optimization and conservation, shielding efficacy is known to depend on a high flexibility of V1V2 giving rise to its substantial sequence variability. How entry competence of the trimer is maintained despite the continuous emergence of antibody escape mutations within V1V2 has not been resolved. Since HIV cell-cell transmission is considered a highly effective means of virus dissemination, we investigated whether cell-cell transmission may serve to enhance infectivity of V1V2 variants with debilitated free virus entry.

Results: In a detailed comparison of wt and V1V2 mutant envelopes, V1V2 proved to be a key factor in ascertaining free virus infectivity, with V1V2 mutants displaying significantly reduced trimer integrity. Despite these defects, cell-cell transmission was able to partially rescue infectivity of V1V2 mutant viruses. We identified two regions, encompassing amino acids 156 to 160 (targeted by broadly neutralizing antibodies) and 175 to 180 (encompassing the a4ß37 binding site) which were particularly prone to free virus infectivity loss upon mutation but maintained infectivity in cell-cell transmission. Of note, V1V2 antibody shielding proved important during both free virus infection and cell-cell transmission.

Conclusions: Based on our data we propose a model for V1V2 evolution that centers on cell-cell transmission as a salvage pathway for virus replication. Escape from antibody neutralization may frequently result in V1V2 mutations that reduce free virus infectivity. Cell-cell transmission could provide these escape viruses with sufficiently high replication levels that enable selection of compensatory mutations, thereby restoring free virus infectivity while ensuring antibody escape. Thus, our study highlights the need to factor in cell-cell transmission when considering neutralization escape pathways of HIV-1.
\end{abstract}

Keywords: HIV, Cell-cell transmission, V1V2, Entry, Neutralization, Antibody escape

\section{Background}

The HIV-1 envelope trimer, consisting of three gp120 gp41 heterodimers, is responsible for mediating HIV entry into target cells and is the sole target of neutralizing antibodies elicited in HIV infected individuals [1,2]. The variable loops 1 and 2 (V1V2) of gp120 are a key component in shaping the envelope's susceptibility to neutralization and have long been known to potently

\footnotetext{
* Correspondence: trkola.alexandra@virology.uzh.ch

'Institute of Medical Virology, University of Zurich, Zurich, Switzerland

Full list of author information is available at the end of the article
}

shield the trimer against antibody attack [3-13]. Mutations triggered by antibody escape are regarded as the driving force of the high intra- and inter-patient sequence variation of the V1V2 domain [14,15]. Despite its seemingly high adaptability, mutations within V1V2 can impair envelope trimer functionality and integrity as the domain mediates intra- and inter-gp120 subunit interactions at the apex of the envelope spike [16-18]. Numerous naturally occurring V1V2 mutations as well as deletion of the entire domain were described to either obliterate or strongly reduce virus infectivity [3,9,19-25]. 
Besides its role for trimer integrity, the V1V2 domain prevents premature adoption of the CD4-bound trimer conformation [16-18,26,27]. This is of importance for preserving a metastable trimer structure that upon receptor binding and structural rearrangements provides the energy required to complete the entry process $[1,28,29]$. Secondly, the closed, non-CD4 triggered trimer conformation secures shielding of neutralization-sensitive domains from antibody attack [3-13]. The epitopes profiting most from V1V2 shielding include the V3 loop, situated beneath V1V2 in the intact trimer, the CD4 binding site and CD4-induced epitopes important for co-receptor binding [3-13]. In summary, the available data show that disturbance of the quaternary orientation of V1V2 and $\mathrm{V} 3$ at the spike apex, either due to deletion of V1V2 or mutations within or outside V1V2, result in high increases in neutralization sensitivity to antibodies directed against these epitopes. In parallel, mutations leading to V1V2-induced transitions from a closed to an open trimer configuration result in reductions of virus entry capacity and trimer stability [3-13,19-25].

Contrasting its role in shielding against neutralizing antibodies, the V1V2 domain itself is a target of the neutralization response. Despite the high genetic variability of V1V2, certain sequence motifs are highly conserved across strains and are targeted by broadly neutralizing antibodies (bnAbs) (reviewed in [30]). These bnAb epitopes, including those of PG9 and PG16, CH01 to $\mathrm{CH04}$, and PGT141 to PGT145, are formed by amino acid residues in V1V2, glycans originating from V1V2 and, in some cases, parts of V3 [31-34]. The importance of $\mathrm{V} 1 \mathrm{~V} 2$ as a potential vaccine target was recently underscored by the results of the RV144 vaccine trial, with antibodies directed against V1V2 being the main correlate of protection [35-38]. However, due to the low constraints on V1V2 sequence conservation, evidenced by the high frequency of single point mutations, length polymorphisms and changes in glycosylation pattern, escape to neutralizing antibodies directed against V1V2 or domains shielded by V1V2 develops rapidly [10,24,39-48]. A better understanding of the escape pathways that allow V1V2 to steer neutralization sensitivity and their consequences for viral infectivity and transmission is thus pivotal to support and guide vaccine design.

Here, we describe a detailed analysis of functional properties of V1V2 during the HIV-1 entry process. Specifically, we explored whether cell-cell transmission may be a potential rescue path for viruses with low entry capacity due to alterations in V1V2. Infectivity during cellcell transmission has been estimated to be several orders of magnitude higher than free virus infection [49-54] and can overcome barriers to free virus infection including low target cell infectability, low virus production in infected cells, or low virus stability [55-57]. Due to its dual roles of shielding against neutralization and ensuring trimer integrity, resistance evolution of V1V2 is likely an iterative process that frequently generates virus variants with decreased replication capacity that require compensating mutations to thrive. Hence, we hypothesized that if emerging V1V2 mutants retain partial cellcell transmission capacity, this would enable the virus to maintain debilitating resistance mutations while sampling compensatory mutations to restore free virus infectivity. Utilizing cell-cell transmissibility would indeed be doubly beneficial for the virus as it may not only boost infectivity but also provide a sheltered environment largely refractory to antibody neutralization $[49,58,59]$. As we show here, cell-cell transmissibility is indeed better preserved than free virus infectivity among naturally occurring and engineered V1V2 mutant envelopes. Hence, cell-cell transmission may constitute an important salvage pathway for replication of antibody escape variants, highlighting the need to factor in cell-cell transmission when considering antibody escape pathways of HIV-1.

\section{Results}

\section{Dissecting the influence of the V1V2 domain during different virus entry pathways}

Virions produced by an HIV-infected cell can infect distant target cells as free virus or transfer directly to a neighboring cell via formation of a virological synapse, the canonical cell-cell transmission pathway $[49,60]$. Dissecting the relative contribution of the two entry modes requires assay formats that shift the entry process to one pathway while limiting or obliterating the other. As the aim of our study was to explore differences in V1V2 functionality during HIV-1 free virus infection and cellcell transmission, we chose assay formats that (i) distinguish between the two entry modes, (ii) allow comparisons of the respective entry efficacies, and (iii) yield comparable results across a range of target and donor cells (Additional file 1). To establish and validate our assay setups we analyzed a panel of four JR-FL env variants for their cell-cell transmission and free virus entry capacity. Besides JR-FL wildtype (wt) we probed the V2 point mutant JR-FL I165P (that has no impact on free virus infectivity and served as control) and V2 point mutations L175P [11] and D180N [61], which were previously described to interfere with env structural integrity and neutralization sensitivity.

To probe HIV-1 cell-cell transmission we utilized a recently introduced reporter system [56,62], which is based on co-transfection of virus producer cells with a Gaussia Luciferase reporter (inGLuc) together with plasmids encoding HIV. As described [56,62], an intron in the GLuc reporter gene and its reversed orientation in the vector prevents reporter signals from transfected donor cells or upon donor-target cell fusion (Figure 1A). Gaussia Luciferase is only produced in target cells upon 


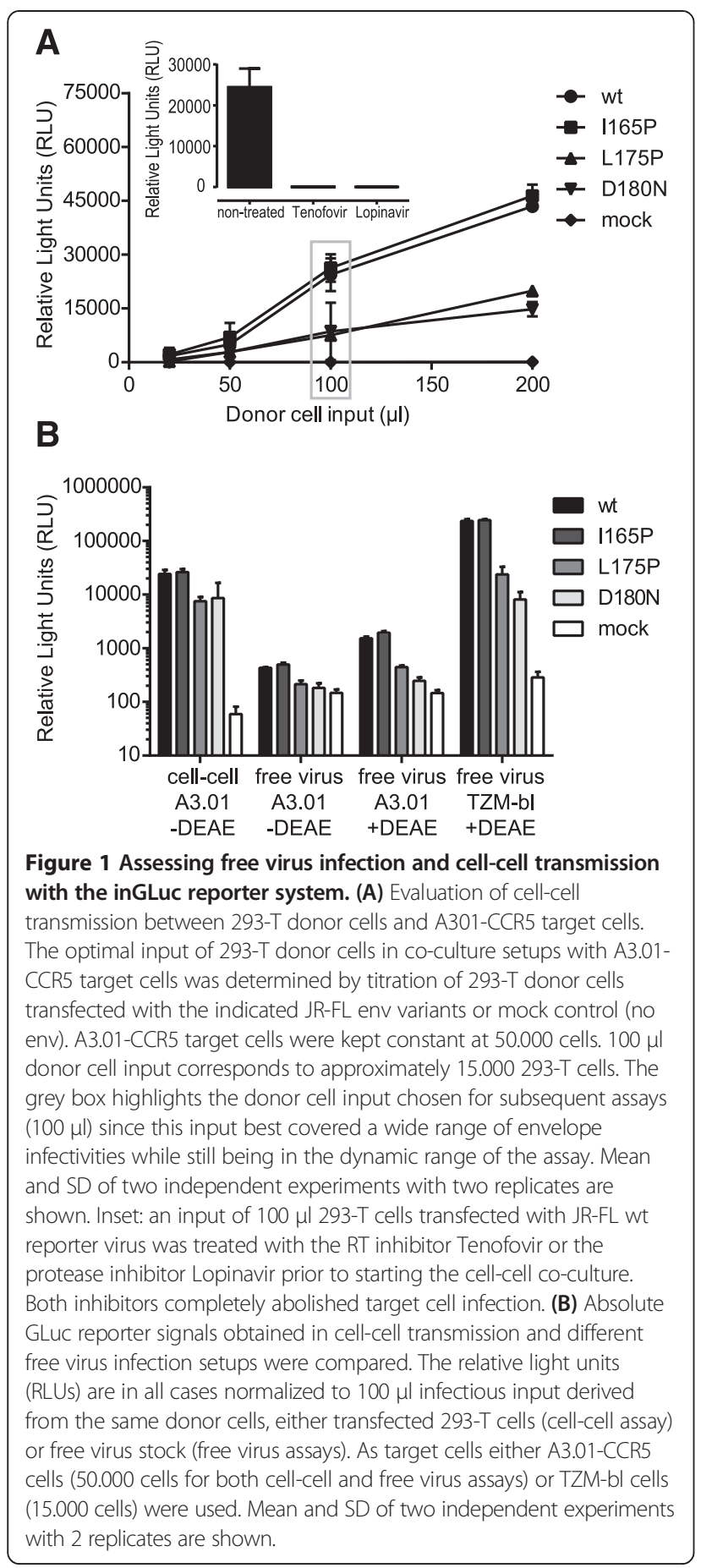

successful infection by viruses that contain the inGLuc reporter and that entered either as free virus or via cell-cell transmission (Figure 1A). To monitor genuine cell-cell transmission we restricted free virus infection by omitting DEAE dextran in the co-culture medium, which we previously showed to limit infection of transformed cell lines by free virus but not cell-cell transmission (Figure 1B and [58]). Free virus infectivity was assessed in parallel using single cycle virus infection assays. To assure maximal comparability between free virus infection and cell-cell transmission, we employed cells transfected with HIV encoding plasmids and the inGLuc reporter as donor cells in cell-cell transmission setups and in parallel harvested virus-containing supernatant from the same batch of donor cells to probe free virus infection (Additional file 1).

To compare efficacies of free virus infection and cell-cell transmission one can choose between two virus input standardizations: at the level of the target cell or at the level of the donor cell. We chose the latter as we were interested to explore if virions produced by a donor cell are more infectious during cell-cell transmission or free virus infection. A set number of donor cells were used as input in cell-cell transmission assays and corresponding aliquots of donor cell culture supernatant containing free virus was used as free virus input (Additional file 1). We determined the optimal input of donor cells by titration to ascertain GLuc signals within the dynamic range of the assay (Figure 1A). To perform matched comparisons of free virus and cell-cell infectivities, we harvested both donor cells and virus supernatant from a 12-well culture and adjusted both to a total volume of $1 \mathrm{ml}$, which allowed us to express cell-cell and free virus input in $\mu \mathrm{l}$ volumes throughout our further analysis (Figure 1 and Additional file 1). As an input of $100 \mu \mathrm{l}$ donor cell suspension (15.000 cells) provided the best dynamic range for assessing cellcell transmission (Figure 1A), we used the corresponding amount of free virus $(100 \mu \mathrm{l})$ as maximum volume in titrations for free virus infection (Figure 1B and Additional file 1).

For direct comparison of infectivities in both transmission modes culture conditions should be as similar as possible. We thus assessed both transmission modes in medium lacking DEAE. When we compared absolute infectivities of the JR-FL env panel we found that levels of infection were considerably higher during cell-cell transmission than during free virus infection (Figure 1B). Cell-cell transmission of JR-FL wt env was 80-fold more effective than free virus infection, in agreement with previous reports $[49-51,60,63]$. Free virus infectivity of env mutants L175P and D180N in absence of DEAE was only marginally above mock infected control and hence proved too low to ensure accurate detection (Figure 1B). Since quantitative comparisons of cell-cell transmission and free virus infection across viruses with different infectivities under identical culture conditions was therefore not feasible, we additionally probed free virus infectivity in presence of DEAE. Although addition of DEAE improved free virus infectivity of A3.01-CCR5 cells, absolute signals were still comparatively low, with the GLuc signal for JR-FL wt being only about 10-fold above the signal from mock-infected cells. In contrast, 
free virus infectivity on TZM-bl cells in presence of DEAE yielded high GLuc signals in the range of A3.01CCR5 cell-cell transmission, with GLuc signals for JR-FL wt on TZM-bl cells being 150-fold higher than on A3.01-CCR5 cells in presence of DEAE (Figure 1B). A further advantage of the TZM-bl system was its wider dynamic range (850-fold difference between the signals of JR-FL wt and mock). Most importantly however, we observed the same pattern of free virus infectivity for the different env mutants on both A3.01-CCR5 and TZM-bl cells. Thus, we had the possibility to assess free virus infectivity with either target cell line. Regarding our interest in obtaining precise estimates of free virus entry capacity of env variants over a wide range of infectivities, we chose to use TZM-bl cells in presence of DEAE for assessment of free virus entry due to the high dynamic range and robust signals obtained in this assay.

\section{The V1V2 domain differentially influences free virus infection and cell-cell transmission}

Concerning the role of V1V2 in shaping virus transmission we were specifically interested in addressing two aspects: i) differences in the efficacy of wt and mutant viruses within a certain transmission mode, and ii) comparison of the infectivity patterns between the two transmission modes. To enable these comparisons we calculated relative infectivities in each assay format (cell-cell or free virus infection) by normalizing the obtained mutant env infectivity to the respective wt env (Additional file 2). The derived relative infectivities (\% of wt) were used to compare if and in which transmission mode env variants loose or gain activity compared to wt env.

Comparing the relative infectivities of the four JR-FL env variants shown in Figure 1 revealed that both cell-cell transmission and free virus infection of the L175P and D180N mutants was substantially decreased compared to wt. However, the two mutants maintained significantly higher infectivity during cell-cell transmission (2.5 and 3.9 fold higher cell-cell transmission than free virus infectivity of L175P and D180N, respectively; Figure 2A).

To ensure that the results from our cell-cell transmission assay, which utilizes 293-T cells as donor cells, were also valid for $\mathrm{T}$-cell to $\mathrm{T}$-cell transmission, we studied virus transmission between Jurkat (donor) and A3.01CCR5 (target) cells (Additional file 1). Since transfection of Jurkat cells with HIV pseudotyping plasmids yielded only low levels of virus producing cells (data not shown), we transfected Jurkat cells with replication competent (rc) infectious molecular clones carrying JR-FL wt or mutant envs and the inGLuc vector (rc-TN6 ${ }^{\text {inGLuc }}$ ) and assessed Jurkat to A3.01-CCR5 cell-cell transmission in absence of DEAE (Figure 2B and Additional file 1). Jurkatderived free virus was probed in parallel for infectivity on
TZM-bl cells in presence of DEAE as described. We observed the same pattern as with the 293-T donor cells, with free virus infectivity of the L175P and D180N mutants reduced to levels of $30 \%$ and $36 \%$ of wt infectivity, respectively. Cell-cell transmission capacity of the mutant envs remained at significantly higher levels with $78 \%$ and $61 \%$ of wt infectivity. This represents 2.6 -fold and 1.7 -fold increases in cell-cell transmission capacity over free virus infectivity for the L175P and D180N mutant, respectively (Figure 2B). Of note, the relative infectivity of the Jurkatderived L175P and D180N mutant rc-TN6 ${ }^{\text {inGLuc }}$ viruses on TZM-bl cells as free virus (Figure 2B) was higher compared to the 293-T derived viruses (Figure 2A) (30\% versus 9.6\% and $36 \%$ versus $4.2 \%$ for Jurkat and $293-\mathrm{T}$ derived L175P and D180N virions, respectively), highlighting the influence of donor and target cells in virus transmission as previously suggested $[56,62,64]$. However, the overall infectivity pattern remained the same: regardless of the donor cells used, the relative infectivity of cell-cell transmission was higher than infectivity in free virus transmission (Figure 2A and B). Thus, since 293-T donor cells yielded results comparable to Jurkat donor cells and additionally offered the possibility to work with env pseudotyped viruses, we subsequently utilized the 293-T to A3.01-CCR5 cell-cell transmission assay for the majority of analyses.

To obtain further insight on the entry properties of mutant envs we probed their functionality during cellcell-fusion (Figure 2C). Although cell-cell fusion is not a relevant entry mode leading to productive infection, we reasoned that assessing fusion may yield important insights on env functionality, especially for envs that are strongly impaired in both free virus infection and cell-cell transmission. Env fusion capacity and free virus infectivity were determined in parallel using a LTR-GFP reporter construct. As observed for the inGLuc reporter viruses, the $\mathrm{L} 175 \mathrm{P}$ and $\mathrm{D} 180 \mathrm{~N}$ mutants were severely impaired in free virus infectivity (15\% and $12 \%$ of wt activity for L175P and D180N, respectively; Figure 2C). This severe reduction in free virus entry capacity was not reflected in the fusion capacity of the envs, as fusogenicity was maintained at comparatively high levels (60\% and $43.5 \%$ of wt activity for L175P and D180N, respectively). Since assessment of fusion capacity thus provided additional information on entry functionality, this analysis was included in our further characterization of env mutants.

\section{V1V2-deleted viruses lose free virus entry capacity but retain cell-cell transmission and fusion activity}

Since the JR-FL V2 mutants L175P and D180N showed strong reduction in both free virus and cell-cell transmission infectivity we were interested to define the overall impact of the V1V2 domain on virus transmission. To 


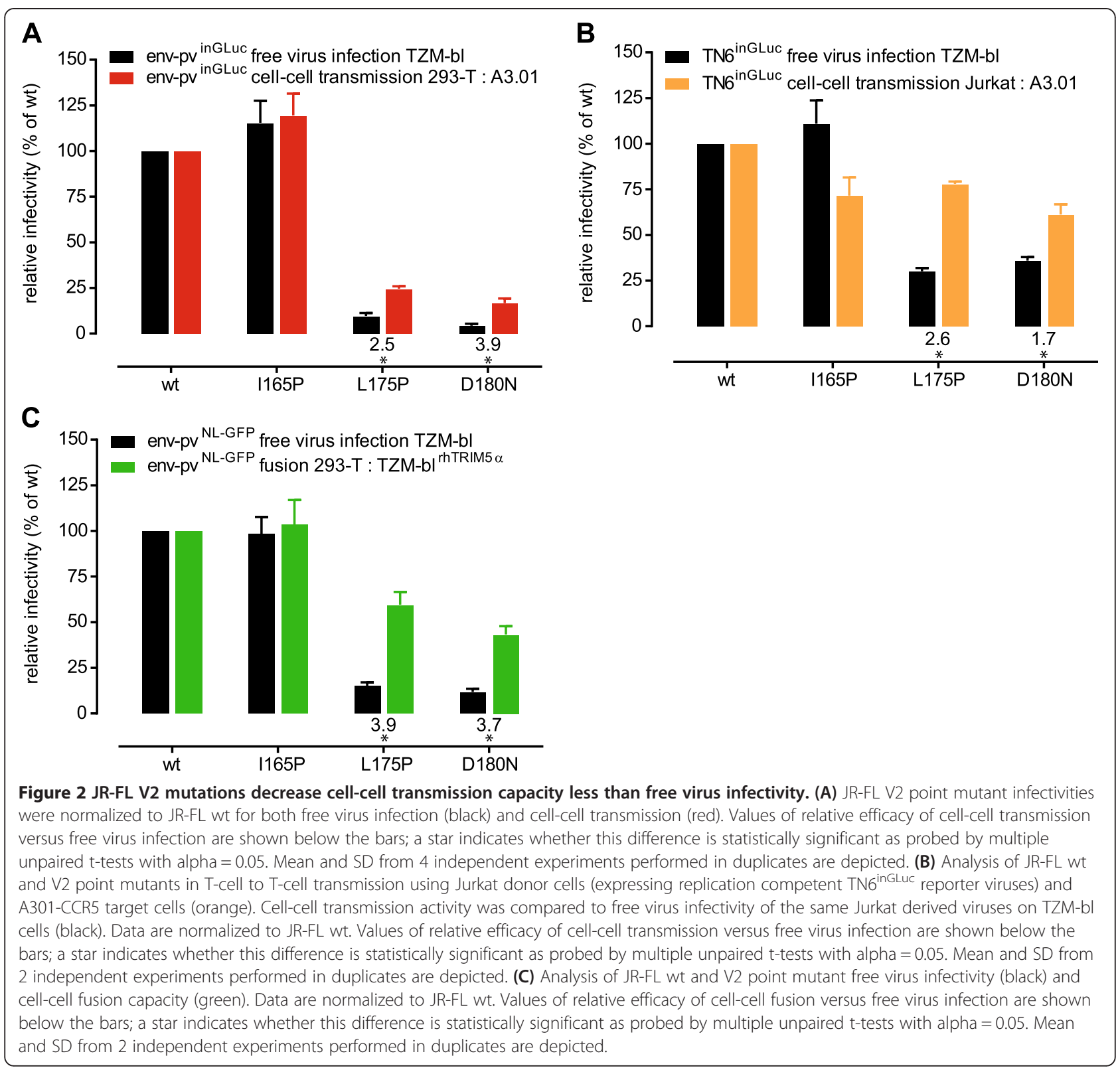

this end we probed a panel of 10 viruses, encompassing subtype B Tier-1A viruses (SF162, NL4-3), subtype B Tier2 viruses (JR-FL, RHPA, AC10, REJO, ZA110) and subtype C Tier-2 viruses (CAP88, ZM109, ZM214) to support free virus infection, cell-cell transmission and cell-cell fusion as wt and upon V1V2 deletion (Figure 3). While V1V2 deletion will not occur in vivo, the deletion mutants allowed us to obtain an assessment of the general contribution of the V1V2 domain to the different entry pathways across different virus strains as the impact of single point mutations can differ based on the envelope background probed.

When we assessed the infectivity of strain ZA110 in presence and absence of V1V2 in T-cell to T-cell transmission using Jurkat donor and A3.01-CCR5 target cells, we found that free virus infectivity of the V1V2deleted env was reduced to $32 \%$ of wt level (Figure 3A). In contrast, cell-cell transmission capacity was maintained at $65 \%$ of wt level, representing a 2 -fold higher efficacy of cell-cell transmission capacity compared to free virus infection (Figure 3A).

We extended our analyses to the panel of $10 \mathrm{wt}$ and V1V2-deleted envs and probed them in 293-T to A3.01CCR5 cell-cell transmission (Figure 3B). In agreement with previous reports [3,9,19-25], free virus entry capacity was strongly reduced upon V1V2 deletion. As observed for JR-FL V2 point mutants (Figure 1 and 2), the capacity of V1V2-deleted envs to support cell-cell 


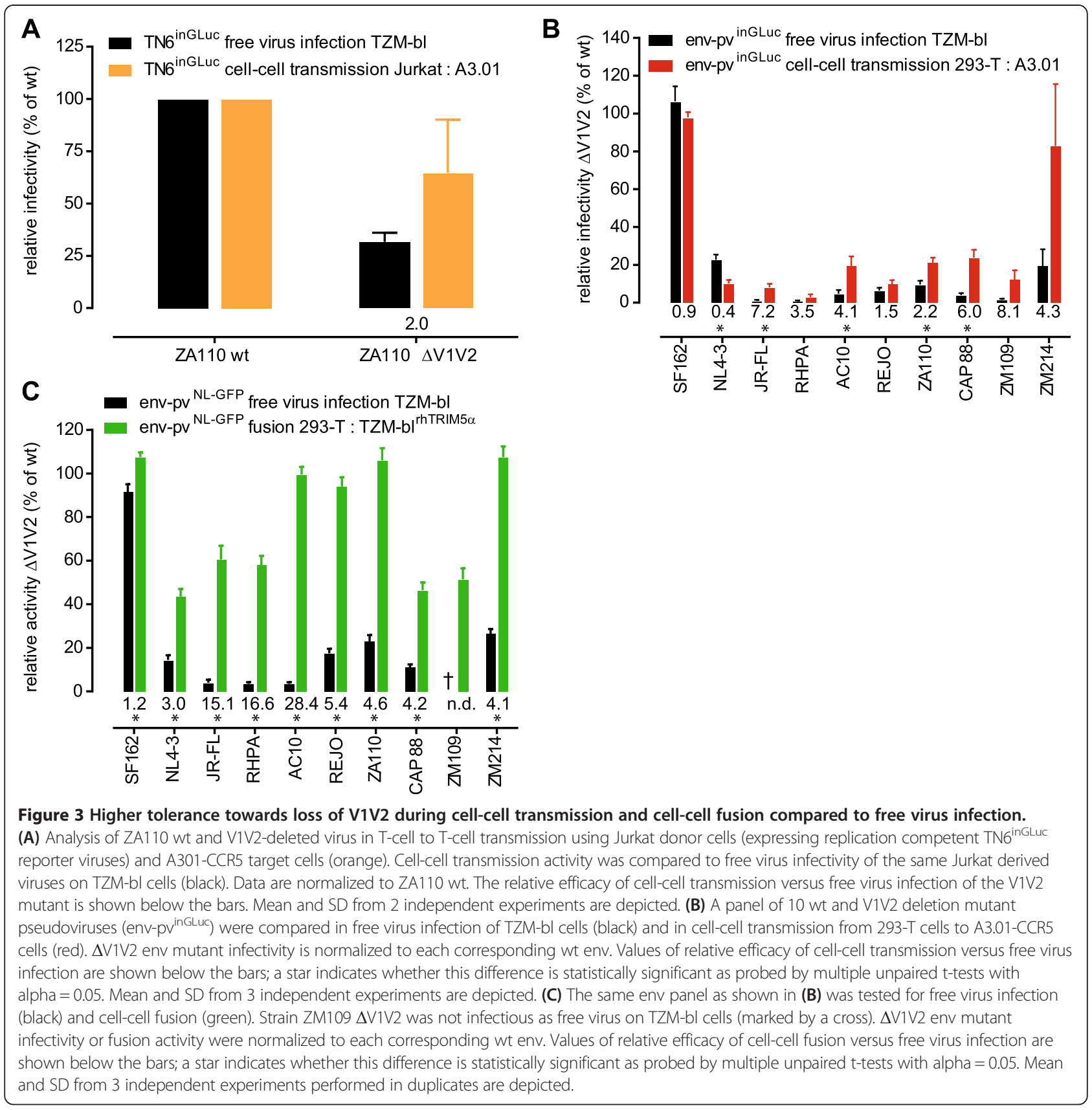

transmission was lower compared to wt envs but generally exceeded free virus infectivity (Figure 3B). One exception was NL4-3 $\Delta \mathrm{V} 1 \mathrm{~V} 2$, the only virus in our panel which proved not to excel free virus infectivity during cell-cell transmission. The other exceptions were SF162 $\Delta \mathrm{V} 1 \mathrm{~V} 2$ and ZM214 $\Delta \mathrm{V} 1 \mathrm{~V} 2$, which both retained cellcell transmission activity at or close to wt level $(96 \%$ and $83 \%$ of wt, respectively). This was especially notable for ZM214 as this virus, in contrast to SF162, showed markedly decreased infectivity as free virus upon V1V2 deletion. For the Tier-1A env clone SF162 the V1V2 domain seems to be completely dispensable for both free virus entry and cell-cell transmission. This is in line with the presumed open trimer conformation of SF162 in which the V1V2 does not perform the extent of interprotomeric contacts required for shielding $[9,20]$. In sum, with the exception of NL4-3, all V1V2-deleted viruses retained partial cell-cell transmission activity, with no or comparatively lower loss in activity as seen during free virus transmission. The observed relative activities were 1.5 to $>8$-fold higher in cell-cell transmission than in free virus infection (Figure 3B). Since both free virus infection and cell-cell transmission of V1V2-deleted envs were strongly reduced compared to wt, we ascertained 
that the RLU signals obtained in the respective entry assays were clearly above background and within the dynamic range of the assays (Additional file 3 ).

Interestingly, the capacity of V1V2-deleted envs to mediate cell-cell fusion remained in most cases intact (Figure 3C; 40 to $120 \%$ of wt fusion activity). Fusogenicity and free virus infectivity were not tightly linked in our panel, as for instance AC10, an envelope with the lowest free virus infectivity upon V1V2 deletion, retained fusion activity at almost wild type levels (Additional file $4 \mathrm{~A})$. In contrast, the other three viruses with comparatively low entry efficacy upon V1V2 deletion (JR-FL, RHPA and ZM109) all showed reduced fusion capacity (60.5\%, 58\% and $51.5 \%$ of wt fusogenicity, respectively). Overall, cell-cell fusion activity was maintained at higher levels (up to $>25$-fold relative activity over free virus infectivity) than cell-cell transmission (Figure 3B and C).

\section{Influences of the V1V2 domain on virion trimer content and stability}

While V1V2-deleted envs were expected to show pronounced defects in free virus entry [3,9,19-25], the high capacity of these envs to retain cell-cell transmission and cell-cell fusion activities was surprising. We therefore sought to dissect functions of V1V2 that are required for free virus entry but are, at least partially, dispensable during cell-cell transmission. Since V1V2 is a central component of the trimer required to maintain its integrity and stability [3,9,19-25], V1V2 deletion could potentially inflict a lower density of functional env trimers on virions that may cause the observed loss of free virus infectivity. To investigate potential decreases in env content we probed whether V1V2 deletion results in lower env expression on producer cells, decreased env incorporation into virions, or an increased propensity to CD4 induced gp120 shedding from trimers (Figure 4 and Additional file 5). Expression of V1V2-deleted envs on transfected 293-T cells was comparable to the corresponding wt envs ( 80 to $>100 \%$ of wt; Additional file 5A and B). Similarly, levels of $\triangle \mathrm{V} 1 \mathrm{~V} 2$ gp120 content of virions was in the range of wt for 8 of the 10 viruses probed ( $>80 \%$ of wt content, Additional file $5 \mathrm{C}$ ). The strongest decrease was observed for ZM109 $\Delta \mathrm{V} 1 \mathrm{~V} 2$, which only reached $10 \%$ of wt ZM109 gp120 levels and was not functional in free virus entry (Figure $3 \mathrm{C}$ ). The second strain with lower gp120 content on virions was JR-FL $\triangle$ V1V2 which reached only $40 \%$ of wt levels. A more marked difference between wt and $\triangle \mathrm{V} 1 \mathrm{~V} 2$ envs was apparent in their susceptibility to CD4-induced gp120 shedding, with V1V2-deleted envs showing a higher propensity to gp120 dissociation upon CD4 binding in line with previous reports on the reduced stability of V1V2 deleted envs [26,27] (Figure 4A). To probe the physical stability of $\Delta \mathrm{V} 1 \mathrm{~V} 2$ virions in more detail, we
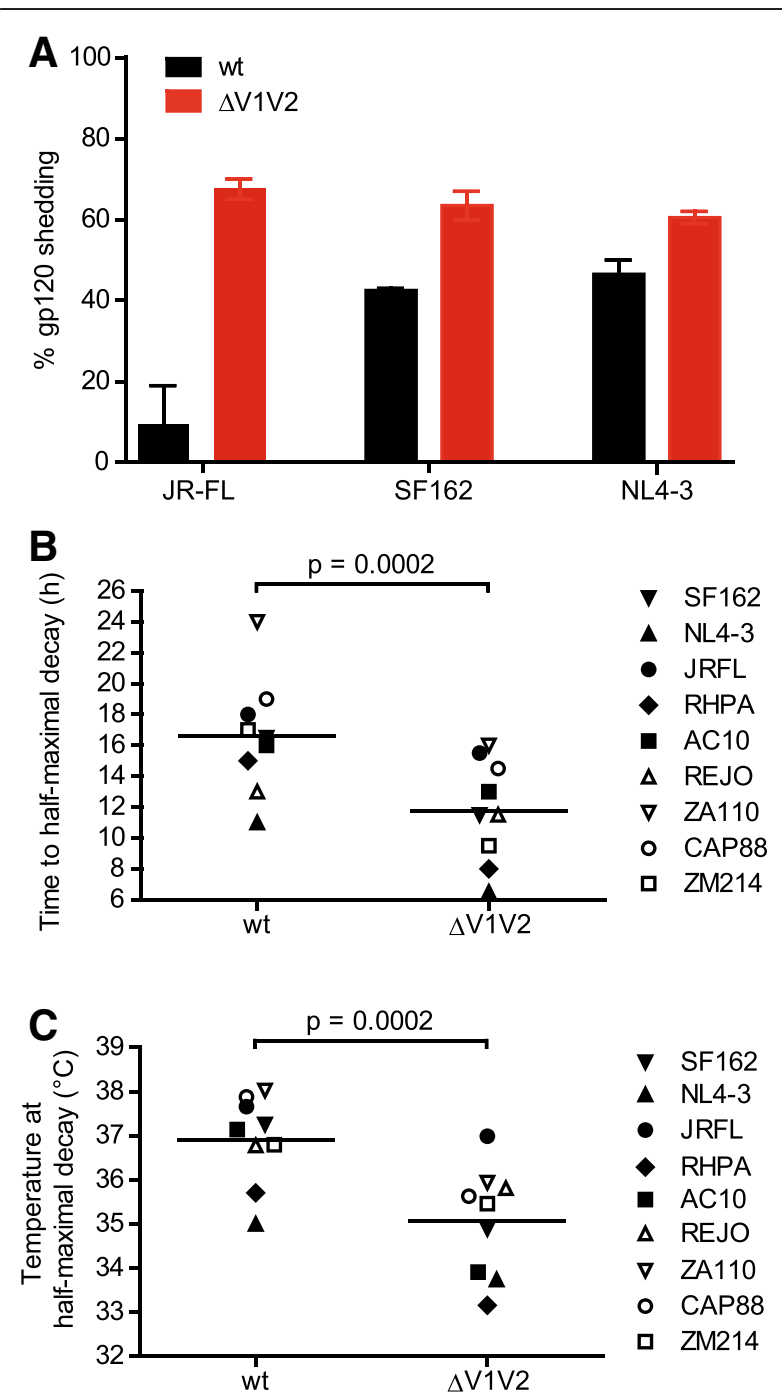

Figure 4 V1V2 deletion impacts on trimer stability.

(A) Susceptibility of wt (black) and $\Delta$ V1V2 envs (red) to CD4-induced shedding was probed on env-transfected 293-T cells by flow cytometry. Percent of gp120 shedding upon incubation of envexpressing cells with CD4-lgG2 in relation to mock-treated controls is shown. Bars depict mean and SD of 2 independent experiments. (B) The half-life of wt and $\Delta$ V1V2 env virus stocks was determined by incubation for up to $80 \mathrm{~h}$ with periodic sampling and infectivity assessment on TZM-bl cells. Data points are means from 2 to 3 independent experiments. (C) Wt and $\Delta \mathrm{V} 1 \mathrm{~V} 2$ virus stocks were subjected for $5 \mathrm{~h}$ to temperature gradient from $25^{\circ} \mathrm{C}$ to $45^{\circ} \mathrm{C}$ in $2.5^{\circ} \mathrm{C}$ steps followed by infectivity assessment on TZM-bl cells. The temperatures at which $50 \%$ infectivity of each stock remained are depicted. Data points are means of 2 to 3 independent experiments performed in duplicates.

analyzed temperature-induced virus infectivity decay in two different assays. The half-life of wt and V1V2deleted virus stocks was determined by incubating virus samples at $37^{\circ} \mathrm{C}$ for up to $80 \mathrm{~h}$ and determining infectivity in regular intervals (Figure 4B and Additional file 6). 
The stability of wt envs proved to vary over a wide range. The most rapid decay was observed for the Tier-1A strain NL4-3, the highest stability displayed the Tier-2 env ZA110 with an half maximal decay time of 24 h. Interestingly, V1V2-deleted viruses displayed significantly faster decay rates than wt envs (Figure 4B; paired $t$ test $\mathrm{p}=0.0002$, mean time to half maximal decay $16.6 \mathrm{~h}$ for wt and $11.8 \mathrm{~h}$ for $\Delta \mathrm{V} 1 \mathrm{~V} 2$ envs). We further performed a temperature escalation treatment of wt and $\triangle \mathrm{V} 1 \mathrm{~V} 2$ viruses by exposing virus aliquots to a temperature gradient ranging from $25^{\circ}$ to $45^{\circ} \mathrm{C}$. When we compared the temperatures at which virus stocks had lost $50 \%$ of their infectivity, we observed a markedly higher sensitivity of V1V2-deleted envs to increasing temperatures (Figure $4 \mathrm{C}$ and Additional file 7; paired $t$-test $\mathrm{p}=0.0002$; mean temperature at which $50 \%$ infectivity loss occurred $36.9^{\circ} \mathrm{C}$ and $35.1^{\circ} \mathrm{C}$ for wt and $\Delta \mathrm{V} 1 \mathrm{~V} 2$ envs, respectively). Infectivity decay rates (Figure 4B) and temperature sensitivity (Figure $4 \mathrm{C}$ ) of wt and $\triangle \mathrm{V} 1 \mathrm{~V} 2$ envs correlated (wt envs: $\mathrm{r}=0.825, \mathrm{p}=0.0062$; $\Delta V 1 V 2$ envs: $\mathrm{r}=0.734, \mathrm{p}=0.0243$; Additional file 8 ). In summary, although we observed a range of reactivities for both wt and $\triangle \mathrm{V} 1 \mathrm{~V} 2$ envs in terms of trimer content and stability, none of the probed parameters by itself proved to shape free virus and cell-cell infectivity (Additional file 4B-G). For instance, although V1V2deleted JR-FL, AC10 and RHPA had a comparably low infectivity as free virus, only JR-FL proved to incorporate lower envelope densities (Additional file 5C). Despite this, the JR-FL $\triangle \mathrm{V} 1 \mathrm{~V} 2$ env was among those envs which were closest to their respective wt in terms of decay rates and temperature stability (Figure $4 \mathrm{~B}$ and $\mathrm{C}$ ).

\section{The V1V2 domain is required for shielding against antibody neutralization during cell-cell transmission}

A key function of V1V2 is shielding of the envelope trimer against neutralizing antibodies [3-13]. However, whether shielding by V1V2 is critical for both free virus infection and cell-cell transmission is currently not known as previous analyses have focused solely on free virus infection. Considering that efficacy of neutralizing antibodies is substantially reduced during cell-cell transmission $[49,58,59,64]$, we thought it prudent to probe whether V1V2 shielding may be of less importance in this entry mode. To assess antibody neutralization during cell-cell transmission we utilized 293-T donor and A3.01-CCR5 target cells, for free virus neutralization 293-T produced virus stocks and TZM-bl target cells and for fusion inhibition 293-T donor and TZM-bl target cells. As shown above (Figure 1), utilizing TZM-bl target cells for free virus neutralization had the advantage that also virus stocks with low infectivity that showed only marginal infectivity of A3.01-CCR5 cells could be probed. Using JR-FL and a panel of neutralizing Abs we verified that free virus neutralization yielded identical results on A3.01-CCR5 and TZM-bl cells (data not shown).

We first investigated sensitivity of strain ZA110 as wt and upon V1V2 deletion against autologous plasma, the non-neutralizing CD4bs Ab b6, the moderately neutralizing V3-directed $\mathrm{Ab} 1.79$ and the weak neutralizing $\mathrm{CD} 4 \mathrm{i} \mathrm{Ab}$ 17b during free virus infection and cell-cell transmission (Figure 5A). The Tier-2 ZA110 wt virus was not neutralized by any of the mAbs and only partially by the autologous plasma, irrespective if probed as free or cell-cell transmitted virus. V1V2 deletion strongly increased sensitivity of free virus to antibody neutralization. Sensitivity to neutralization during cell-cell transmission was also heightened upon V1V2 deletion, but the magnitude of the effect was lower. Cell-cell transmission of ZA110 $\triangle \mathrm{V} 1 \mathrm{~V} 2$ required 6 to 14-fold higher antibody concentrations to reach $50 \%$ inhibition than free virus infection (50\% inhibitory concentration (IC50) free virus infection vs. IC50 cell-cell transmission: b6 $0.42 \mu \mathrm{g} / \mathrm{ml}$ vs. $2.97 \mu \mathrm{g} / \mathrm{ml}$; 17b $0.041 \mu \mathrm{g} / \mathrm{ml}$ vs. $0.59 \mu \mathrm{g} / \mathrm{ml}$; $1.790 .1 \mu \mathrm{g} / \mathrm{ml}$ vs. $0.67 \mu \mathrm{g} / \mathrm{ml})$.

When we compared V1V2 shielding of JR-FL during free virus infection and cell-cell fusion, we observed, in line with earlier reports [3-13], that free virus inhibition by V3, CD4bs and CD4i directed Abs was increased in absence of V1V2 shielding (Figure 5B). In contrast, gp41 directed agents (2F5 and T-20) and the gp120 glycanspecific Ab 2 G12 showed no or only modest changes in activity against wt and V1V2-deleted viruses. As expected, cell-cell fusion of JR-FL wt proved resistant to antibodies while the activity of T-20 was retained. In agreement with free virus neutralization, V3 Abs showed highly improved activity in blocking cell-cell fusion in absence of V1V2. Surprisingly, this was not the case for CD4bs Ab b6 and CD4i Ab 17b, for which V1V2 deletion led to only small increases in neutralization sensitivity. This suggests that under conditions of rapid receptor engagement these weak or non-neutralizing Abs remain less active irrespective of V1V2 shielding.

We next compared plasma antibody activity of 19 individuals chronically infected with HIV-1 of subtypes A, B, $\mathrm{C}, \mathrm{AE}$ and $\mathrm{AG}$ in blocking free virus infection, cell-cell transmission and cell fusion of strains SF162, NL4-3 and JR-FL wt and $\triangle$ V1V2 (Figure $5 \mathrm{C}$ ). Free virus inhibition showed the previously described pattern, with plasma samples having considerable activity against the Tier-1A viruses SF162 and NL4-3 but only low activity against the Tier-2 virus JR-FL (SF162: inhibited by 19 samples at reciprocal $50 \%$ neutralization titers (NT50) up to $10^{5}$; NL4-3: inhibited by 17 samples at NT50 up to $10^{4}$; JRFL: inhibited by 10 samples at NT50 up to $10^{3}$ ). V1V2 deletion increased neutralization activity against SF162 and JR-FL free virus (NT50 up to $10^{6}$ ) in line with improved exposure of V3, CD4bs and CD4i epitopes. 


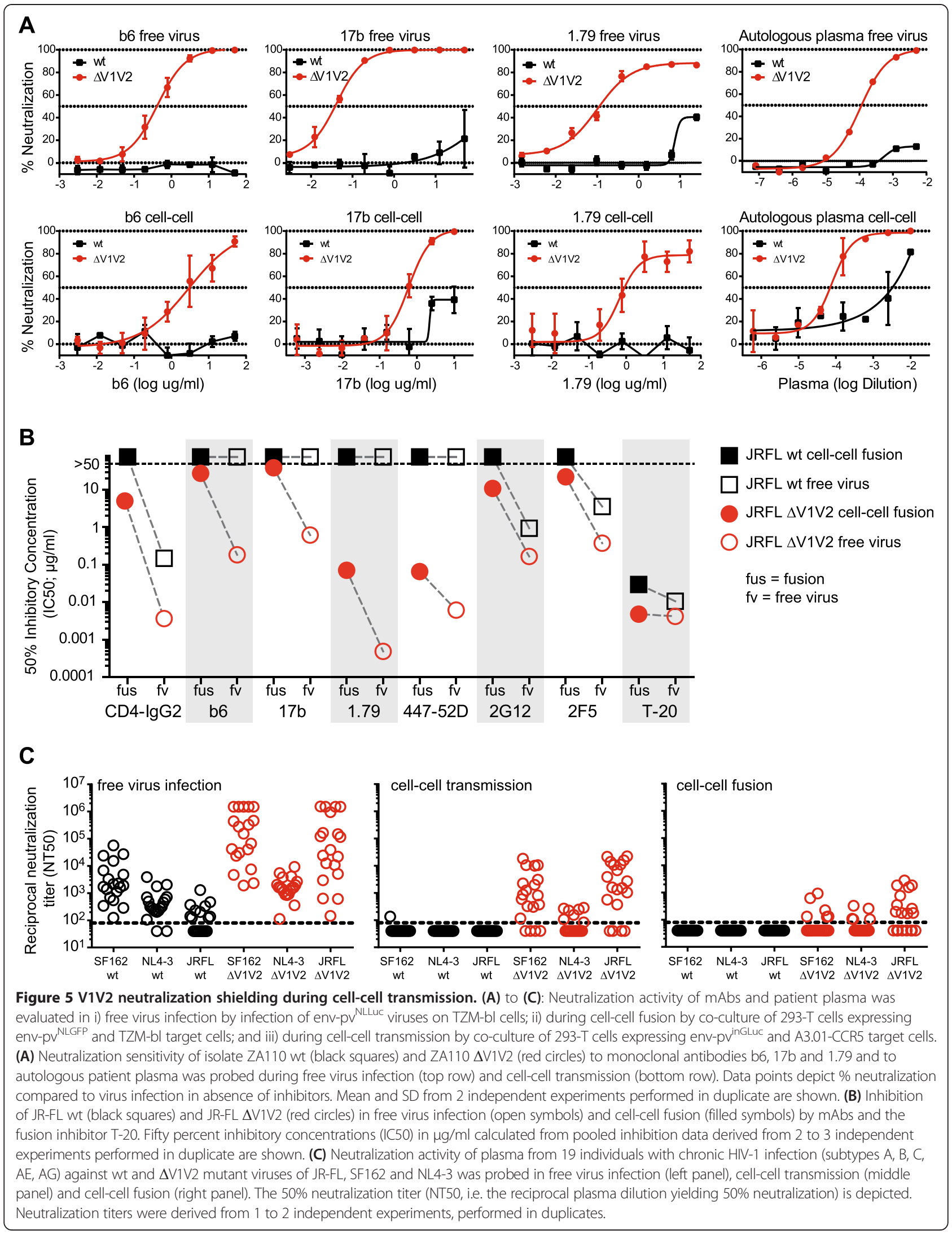


Increase in neutralization sensitivity of NL4-3 upon loss of V1V2 was limited as plasma antibodies to V3 only rarely cross react with the V3 loop of this X4 user [13]. In contrast to free virus inhibition, none of the 19 plasma samples was capable of blocking cell-cell fusion of wt virus and only a fraction of the samples had activity against V1V2-deleted viruses, highlighting that cell-cell fusion is less prone to antibody attack even in absence of V1V2 shielding (SF162 $\triangle \mathrm{V} 1 \mathrm{~V} 2$ : inhibited by 6 samples; NL4-3 $\Delta$ V1V2: inhibited by 5 samples; JR-FL $\Delta$ V1V2: inhibited by 11 samples, all at NT50 below $10^{4}$ ). While wt viruses were equally insensitive to plasma inhibition during cell-cell transmission, cell-cell transmitted viruses lacking V1V2 portrayed an intermediate sensitivity with plasma neutralization potency ranging between free virus neutralization and cell fusion neutralization titers (SF162 $\triangle \mathrm{V} 1 \mathrm{~V} 2$ : inhibited by 15 samples at NT50 below $10^{5}$; NL4-3 $\triangle \mathrm{V} 1 \mathrm{~V} 2$ : inhibited by 7 samples at NT50 below $10^{3}$; JR-FL $\triangle$ V1V2: inhibited by 15 samples at NT50 below $10^{5}$ ). In summary, these data confirm that in cell-cell transmission, similar to free virus infection, intact V1V2 shielding is important for the virus to evade plasma antibody neutralization. However, the consequences upon loss of shielding by V1V2 are less pronounced during cell-cell transmission where neutralization titers were up to 3 orders of magnitude lower than in free virus transmission. Hence, imperfectly shielded viruses are highly likely to benefit from replicating in a cell-cell transmission environment.

\section{Selected V1V2 point mutations differentially affect free-virus infection and cell-cell transmissibility}

While V1V2 deletion mutants served as important tool to dissect the role of V1V2 in the different entry pathways, we thought it prudent to verify the potential in vivo relevance of the observed effects in the context of naturally occurring V1V2 mutations. To investigate which positions in V1V2 are critical to preserve free virus infectivity we compared free virus infection, cellcell transmission and cell-cell fusion capacity of a panel of 24 JR-CSF envs containing mutations of selected residues in V1V2 to alanine [65]. The panel includes residues forming epitopes of previously described V1V2-dependent antibodies $[66,67]$ and/or being part of potential N-linked glycosylation sites shown to be critical for virus infectivity. When we tested the panel in free virus infection and cell-cell transmission we observed strong decreases in free virus infectivity for several of the mutants (Figure 6). Although cell-cell transmission capacity of several mutants was also reduced, infectivity was maintained at higher levels than in free virus infection. The difference was most pronounced for mutants that had the highest impact on free virus infection, including residues 156, 158, 159, 160, 177 and 180. Eight mutants retained free virus infectivity close to wt level (>90\%) or even excelled it. While in all these cases cell-cell transmission was equally high, the I165A mutant was unique, as it was the only mutant that lost cell-cell transmission activity while maintaining high free virus infectivity. Although cell-cell transmission lead to a lower loss in infectivity across all mutants, free virus infectivity and cell-cell transmission capacity were correlated $(\mathrm{r}=0.57, \mathrm{p}=0.0036$, Additional file 9A) indicating that functional properties of the envs exist that govern both transmission modes. This functional link between free virus and cell-cell transmission for the majority of envs was even more evident when envs with high cell-cell transmission capacity and low free virus infectivity (N156A, F159A and Y177A) and the I165A mutant (showing the reverse phenotype), were excluded prior to correlation analysis ( $\mathrm{r}=0.87, \mathrm{p}<0.0001$, Additional file 9B). The cellcell fusion capacity of the env panel showed a similar pattern with fusion capacity being maintained at much higher rates than free virus infectivity. Fourteen viruses reached $\geq 75 \%$ of wt fusion levels and only 4 viruses showed fusion activities below $50 \%$ of wt fusion capacity (Additional file 9C).

In a next step we focused our analyses on V1V2 residue 160 which is a crucial component of the epitope of a class of V1V2-directed broadly neutralizing antibodies represented by PG9 and PG16 [31]. Escape from these antibodies is associated with loss of asparagine at position 160 (N160) which is conserved in more than 90\% of HIV-1 sequences deposited in the Los Alamos HIV sequence database (3719 env sequences included; [68]). PG9/PG16 resistant strains frequently carry a lysine at position 160 (K160). K160 is found in 2.4\% of env sequences in the Los Alamos database. Among viruses probed in our study, 3 envs (SF162, CAP88 and ZM214) encode lysine at position 160. To test the effect on the entry phenotype of this residue, we generated a panel of mutant $\mathrm{N} 160 \mathrm{~K}$ or $\mathrm{K} 160 \mathrm{~N}$ viruses and analyzed their free virus infection and cell-cell transmission capacity. In agreement with previous studies [69], the effect of N160K on free virus entry ranged from a 10 to $90 \%$ loss of entry capacity for the different isolates tested (Figure 7). Notably, in two of the three strains which naturally contain a lysine at position 160, SF162 and CAP88, the K160N mutation reconstituted a potential N-linked glycosylation site and led to a high increase in free virus infectivity, highlighting the importance of this residue for free virus infectivity. In contrast, for strain ZM214 we did not observe a boost in infectivity upon introduction of K160N. Interestingly though, in ZM214 the $\mathrm{K} 160 \mathrm{~N}$ mutation does not restore an $\mathrm{N}-\mathrm{x}-\mathrm{S} / \mathrm{T}$ motif, suggesting that glycosylation at position 160 is required for the observed boost in free virus infectivity. When we tested the panel of N160K mutants in cell-cell transmission (Figure 7) the overall picture was more diverse, indicating that presence or absence of 


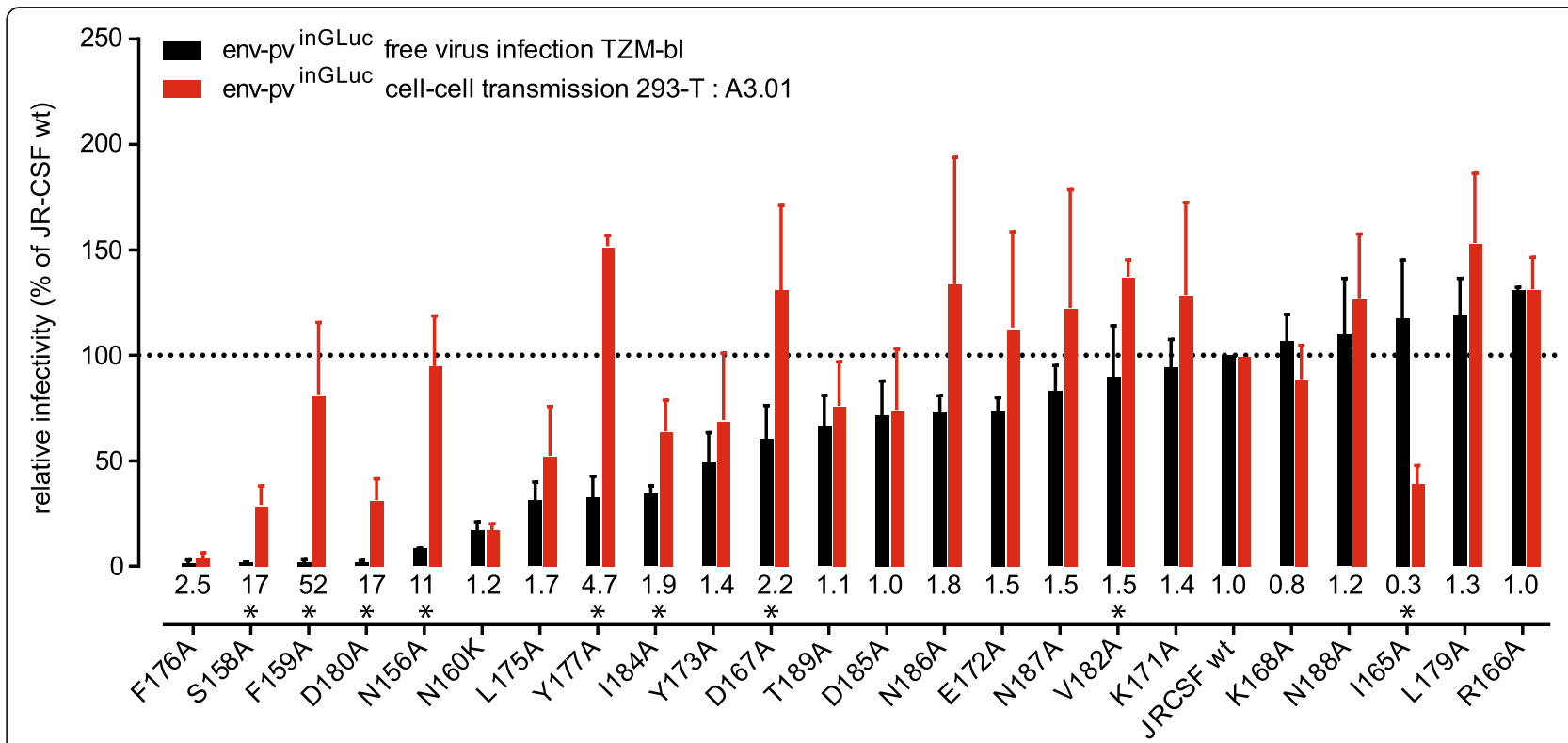

Figure 6 Point mutations in V1V2 reduce free virus infectivity stronger than cell-cell transmission capacity. A panel of JR-CSF V1V2 point mutations was compared for entry efficacy in free virus infection (black) and cell-cell transmission (red). Env mutant infectivities were normalized to JR-CSF wt and are ranked (left to right) in order of increasing free virus infectivity. Values of relative efficacy of each mutant in cell-cell transmission over free virus infection are indicated below the bars; stars depict whether this difference reached statistical significance as probed by multiple unpaired t-tests with alpha $=0.05$. Data shown are means and SD from 3 independent experiments performed in duplicates.

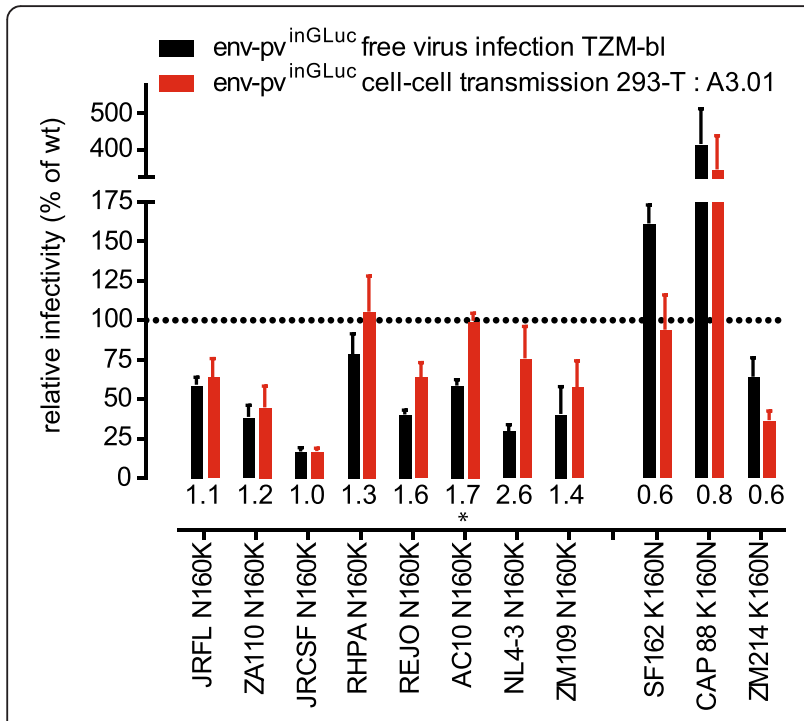

Figure 7 The effect of residue N160 on free virus infection and cell-cell transmission. Eight viruses encoding N160 and 3 viruses encoding K160 were probed as wt and upon N160K or K160N mutation in free virus infection (black) and cell-cell transmission (red). Mutant env infectivity in the two transmission pathways is normalized to the matching wt env. Values of relative efficacy of each mutant in cell-cell transmission over free virus infection are indicated below the bars; stars depict whether this difference reached statistical significance as probed by multiple unpaired t-tests with alpha $=0.05$. Data shown are means and SD from 2 to 3 independent experiments performed in duplicates. the glycosylation site at position 160 has strain-dependent effects on free virus infectivity and cell-cell transmission capacity. Out of the 8 probed mutants, 3 envs had identical or only moderately increased ( $<10 \%$ difference) activity in cell-cell transmission compared to free virus transmission. The remaining 5 viruses showed a higher efficacy of cell-cell transmission (ranging from a 15 to $40 \%$ increase in efficacy compared to free virus infection). SF162 and CAP88 K160N mutant cell-cell transmission efficacy was either equal to wt (SF162) or in the range of free virus transmission (CAP88), but did not excel it, suggesting that glycosylation at position 160 has a greater effect on free virus infectivity than on cell-cell transmission. Cell-cell fusion capacity of the mutants was in all cases maintained at high levels (65 to $100 \%$ of wt; Additional file 10).

\section{Infectivity differences between SF162 and P3N are steered by V1V2 and N160}

The differences in entry efficacy we observed for V1V2 point mutants, in particular N160 variants, were intriguing. To obtain further insights into the interplay of V1V2 variability and infectivity we utilized the Tier-1A strain SF162 and its Tier-3 derivative P3N, which was derived from in vivo evolution via successive transfer of virus in rhesus macaques following initial infection with SHIV-SF162 [70]. Of particular interest for our study, strain P3N has substantial amino acid changes compared to SF162 in V1V2 (Additional file 11), including a switch from the lysine found at position 160 in SF162 to 
asparagine restoring an $\mathrm{N}$-linked glycosylation motif. We therefore analyzed the effect of switching between lysine and asparagine in the parental SF162 and P3N envelopes. In addition we generated a V1V2-deleted version of P3N, as well as swaps of the V1V2 loops between SF162 and P3N. The panel of wt SF162 and P3N and their derivatives containing domain swaps and/or mutations of position 160 were analyzed for free virus infectivity, cell-cell transmission and cell-cell fusion activity (Figure $8 \mathrm{~A}$ and $\mathrm{B}$ ). P3N is highly infectious compared to SF162; however when V1V2 was deleted or replaced with the V1V2 of SF162, the infectivity of P3N dropped to a similar level as SF162, highlighting the importance of V1V2 for the high infectivity of P3N. The opposite effect was less pronounced, as the V1V2 of P3N inserted into SF162 lead to only an approximately 2-fold increase in free virus infectivity, indicating that additional mutations outside V1V2 are required to restore the full infection potential seen for P3N. The N160K mutation in P3N had a negligible impact on infectivity, suggesting that inter-protomeric contacts of P3N are highly optimized and do not depend on a single interaction by N160. In striking contrast, the infectivity of P3N carrying the V1V2 of SF162 could be restored by introduction of N160, highlighting the importance of the N160 glycan for protomer interactions of certain V1V2 domains. When we tested the env panel for cell-cell transmission we observed a similar trend, with SF162-derived mutants remaining close to SF162 wt levels. Notably, P3N wt was approximately 3-fold better than SF162 wt in cell-cell transmission, but more than 7 -fold better in free virus infection (Figure 8A). This further underscores that envs less fit in free virus infection benefit more from cell-cell transmission, while the advantage of free virus entry competent envs is less pronounced in this entry pathway. Similar to free virus infection, the loss in cell-cell transmission capacity observed for the P3N chimera carrying the SF162 V1V2 could be restored by introduction of K160N confirming the importance of this residue in both entry modes. Cell-cell fusion capacity of all envs ranged from $100 \%$ to $250 \%$ of SF162 wt activity (Figure $8 B$ ).

SF162 and SF162 $\Delta$ V1V2 are highly neutralization sensitive viruses (Tier-1A), whereas P3N is highly neutralization resistant (Tier-3). When V1V2 was deleted from P3N, it showed a neutralization phenotype as SF162 $\triangle \mathrm{V} 1 \mathrm{~V} 2$ and was potently neutralized by the V3 specific $\mathrm{Ab} 1.79$ and the CD4bs Ab b6 (Figure 8C). Similarly, replacement of the P3N V1V2 with that of SF162 lead to a neutralization-sensitive phenotype comparable to SF162 wt. In contrast, the V1V2 of P3N introduced neutralization resistance comparable to P3N wt in SF162. Of note, the K160N mutation in both SF162 and P3N.V1V2SF162 resulted in a high increase in neutralization resistance. Thus V1V2, and especially the residue at position 160, is important for maintaining a closed, neutralizationresistant and entry-competent trimer conformation. Probing the association between sensitivity to mAbs 1.79 and b6 and free virus infectivity of the eight viruses confirmed this relationship (correlation analysis: b6 $\mathrm{r}=0.809, \mathrm{p}=$ $0.015 ; 1.79 \mathrm{r}=0.775, \mathrm{p}=0.0238$; Additional file 12). To further determine the influence of V1V2 on entry characteristics, we analyzed the SF162 and P3N wt and V1V2deleted envs for trimer stability. Analysis of temperature stability indicated that P3N was the most stable env out of the four envs tested (Figure 8D and E), providing further evidence that trimer stability is tightly linked with entry competence and neutralization resistance.

\section{Discussion}

The V1V2 domain of gp120 is a key regulator of virus infectivity and shielding against neutralizing antibody attack [3-13,19-25]. Rapid antibody escape mediated by mutations in V1V2 highlights the latter activity and is considered the main driver of the high sequence diversity of the domain $[14,15]$. How the domain supports this high plasticity without jeopardizing entry functionality of the envelope trimer, for which it contributes essential, stabilizing intra- and inter-protomeric contacts $[17,18]$ has not been conclusively resolved. We hypothesized that preserving entry capacity in the face of continuously evolving neutralization escape mutations will require means for the virus to quickly adopt compensatory mutations which rescue infectivity. A prerequisite for this would be that the escape mutants that arise maintain residual entry capacity. We reasoned that cell-cell transmission, being a more efficient mode of virus dissemination than free virus infection [49-57], may play an important role in this context. Since effects of V1V2 variability on cell-cell transmission efficacy have not been assessed to date, we set out in this study to systematically delineate factors that shape entry efficacy of V1V2 variants during free virus infection and cell-cell transmission.

When we tested a panel of $10 \mathrm{HIV}-1$ envs as wt and upon V1V2 deletion, we observed a strong reduction of free virus entry efficiency of V1V2 deleted viruses while their cell-cell transmission and cell-cell fusion capacity was maintained at considerably higher levels (Figure 3). To investigate V1V2 functions that shape entry efficacy we analyzed virion gp120 content, trimer stability and neutralization phenotype (Figures 4 and 5). Expression and virion incorporation levels of wt and V1V2-deleted envs were, with few exceptions, in a comparable range (Additional file 5). However, upon incubation with soluble CD4, the propensity of V1V2 deleted env to gp120 shedding, and therefore trimer inactivation, was increased. Additionally, we observed faster rates of infectivity decay upon prolonged incubation at $37^{\circ} \mathrm{C}$ and a decreased tolerance to temperature increases of V1V2- 


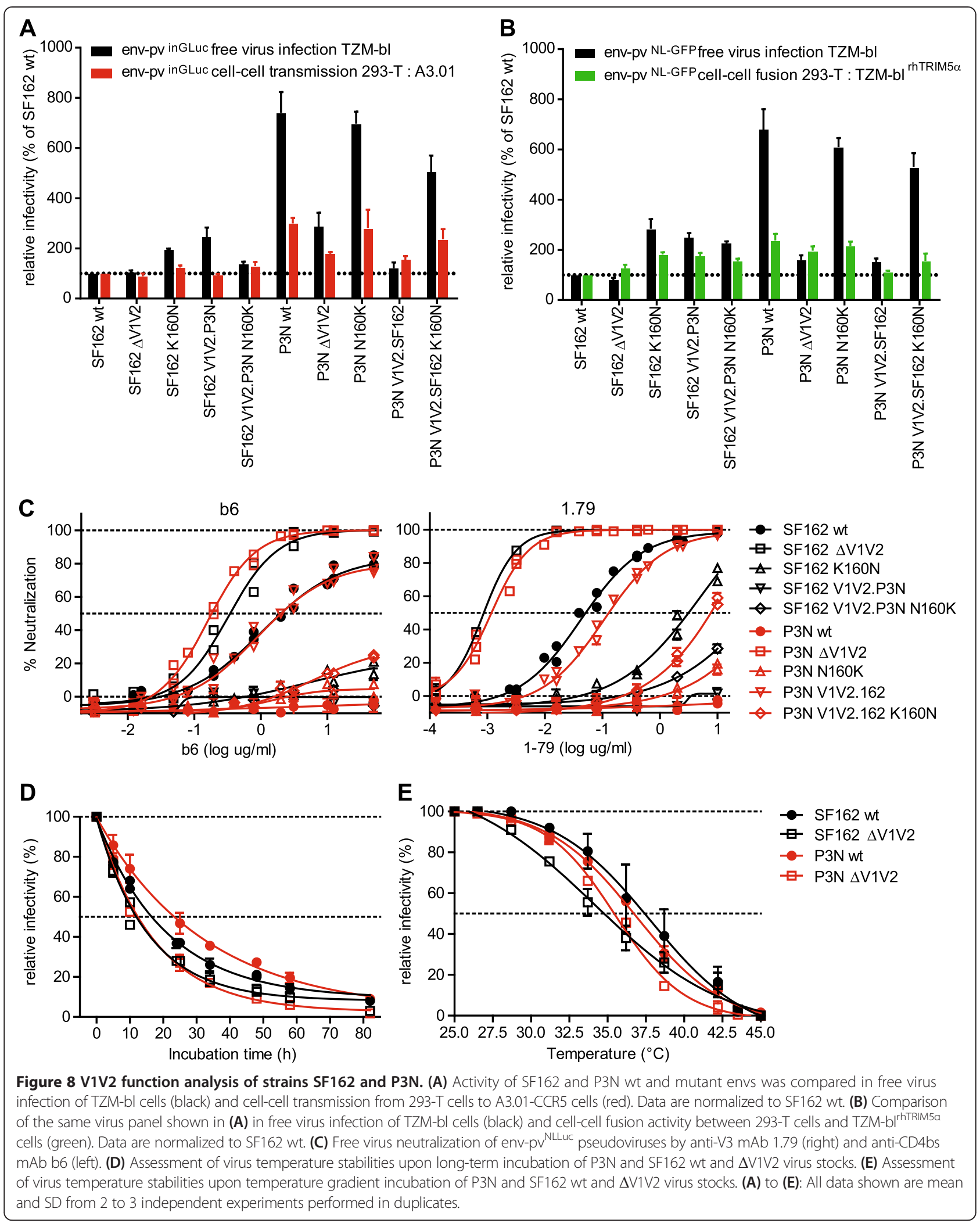


deleted viruses compared to wt. Both observations, higher rates of CD4-induced shedding and faster temperatureinduced infectivity loss of V1V2-deleted envs compared to wt, are in agreement with previous studies showing high propensities of V1V2-mutant env to negotiate transitions to low-energy states and trimer inactivation $[26,27]$. We further found that the V1V2 domain is required for shielding of the trimer against neutralizing antibodies during cell-cell transmission. However, increases in antibody potency upon V1V2 deletion were less pronounced than in free virus infection, indicating that viruses with defects in V1V2 that decrease shielding capacity may benefit from replicating by cell-cell transmission.

A particular emphasis of our study was on studying the influence of physiologically relevant V1V2 mutations on the two entry pathways. We probed a comprehensive panel of V1V2 point mutations and observed similar patterns as with V1V2 deletion, namely an increased capacity of the mutants to retain infectivity in cell-cell transmission while free virus infection was, in several cases, severely impaired. Of particular interest, we observed two "hot spots" where mutations caused strong reductions in free virus entry capacity while cell-cell transmission was retained at significantly higher levels, suggesting that these regions are particularly important for ensuring trimer functionality. These regions were located between residues 156 to 160 and 175 to 180 (Figure 6). The region encompassing residues 156-160 is part of an epitope targeted by antibodies [31-33,48,71], including the broad and potent antibodies PG9, PG16 and PGT145. It is tempting to speculate that this region is preferentially targeted by Abs due to more stringent structural or sequence constraints compared to the rest of V1V2. We explored the entry phenotype of V2 position 160 in more detail, as this residue is crucial for the formation of the epitope of PG9-like antibodies [31,33,34]. Asparagine, as part of an N-linked glycosylation sequon, is the predominant residue at this position with over $90 \%$ sequence conservation [68]. We found that switching between asparagine and lysine (N160K) can dramatically alter both env entry fitness during free virus infection and neutralization phenotype, in agreement with previous studies (Figures 7 and 8) [69,72]. Notably though, cell-cell transmission capacity was less affected than free virus infection by alterations at position 160 , supporting the notion that neutralization escape variants requiring N160 mutation may be rescued via cell-cell transmission. Re-introduction of the glycosylation site at position 160 in strains SF162 and CAP88, which naturally lack a glycosylation motif at this position, induced a strong increase in free virus infectivity. Considering the high conservation of this site across HIV-1 subtypes this may indicate the importance of this glycosylation for HIV to maintain free virus spread in natural infection.
The second hot spot we identified encompasses residues 175 to 180 which have been postulated to mediate gp120 binding to the $\alpha 4 \beta 7$ gut homing receptor. Several reports suggested that binding to $\alpha 4 \beta 7$ fosters efficient infection of $\mathrm{T}$-cell subsets expressing this receptor $[73,74]$, while other studies challenged this view [75,76], currently leaving the physiological importance of $\alpha 4 \beta 7$ interaction unresolved. When we analyzed envs containing mutations of residues that form part of the tripeptide motif LDI/V at the tip of V2 required for $\alpha 4 \beta 7$ binding, we found that especially mutation of the highly conserved aspartate at position 180 induced strong reductions in free virus infectivity, while cell-cell transmission capacity was maintained at higher levels. This phenotype was observed both for JR-FL (Figure 1 and 2) and JRCSF (Figure 6). A3.01-CCR5 cells used in our study can express $\alpha 4 \beta 7$ [77], whereas TZM-bl cells do not. Thus, the strong effect we observed upon mutation of residue 180 may not necessarily reflect a lack of binding to this receptor, but alternatively may indicate the importance of this highly conserved residue for V2 conformation [78,79].

Recent years have substantiated that cell-cell transmission is an effective means of virus transmission, at least in vitro, due to a concentration of virus and receptor molecules in the donor-target cell contact area, rapid infection which outcompetes spontaneous virus inactivation, and a high multiplicity of target cell infection [49-57]. The relevance of cell-cell transmission in vivo remains unresolved [80]; however, cell-cell transmission and even cellcell fusion were recently demonstrated to occur between T-cells in HIV-infected humanized mice [81]. Our observations that viruses carrying envelopes with defects in V1V2 perform better in cell-cell transmission than in free virus infection further highlight the potential for the virus in utilizing the cell-cell transmission pathway. Indeed, our findings may lend themselves towards an improved understanding of virus evolution and spread in vivo. V1V2 is notable for its high sequence diversity, both within the swarm of quasispecies of an infected host as wells as across different HIV subtypes, and may even adopt different conformations on the env trimer $[67,82,83]$. The high sequence variation and structural plasticity of V1V2 is likely required to escape antibody neutralization, including direct escape of V1V2-targeting antibodies and adaptation of its shielding capacity of distal epitopes such as the V3 loop [3-13]. Given the importance of V1V2 for trimer integrity and entry, the obvious question is: how can V1V2 functionality be maintained despite the constantly high sequence variation? Based on our observation that mutations in V1V2 that strongly decrease free virus infectivity can retain cell-cell transmission capacity, we propose that cell-cell transmission may constitute a salvage pathway for the virus (Additional file 13). Upon antibody escape mutations in V1V2 that decrease free virus infectivity, the virus 
may retract to cell-cell transmission until compensatory mutations, either within or outside V1V2 [84-86], may emerge that restore the full infection potential. We suggest that this alternative virus escape pathway should be considered in future approaches towards HIV treatment and vaccine design.

\section{Conclusions}

The V1V2 domain of the HIV-1 envelope glycoprotein gp120 combines two essential functions: It is a key regulator of virus infectivity ensuring the functionality of the envelope trimer and shields the trimer against neutralizing antibody attack. Rapid antibody escape induced by mutations in V1V2 highlights the latter activity and is considered the main driver of the high sequence variability of the domain. How the high mutation rate in V1V2 can be tolerated despite the need to maintain envelope trimer functionality is currently not completely understood. We hypothesized that preservation of entry capacity in the face of continuous neutralization escape mutations will require means for the virus to quickly adopt compensatory mutations which rescue infectivity. A prerequisite for the latter is that the initial escape mutants that arise maintain residual entry capacity. In this study we demonstrate that virus cell-cell transmission, due to its capacity to excel free virus infectivity, can indeed partially rescue infectivity of V1V2 mutant viruses. Hence, cell-cell transmission may provide an important salvage pathway for replication of HIV antibody escape variants until compensatory mutations emerge that restore free virus infection potential.

\section{Methods}

\section{Antibodies and inhibitors}

MAbs were kindly provided by: 2F5 [87] and 2G12 [88] by Dr. Dietmar Katinger, Polymun Scientific, Vienna, Austria. b6 [89] by Dr. Dennis Burton, The Scripps Research Institute, La Jolla, USA. 17b [90] by Dr. James Robinson, Tulane University, New Orleans, USA. 44752D [91] was purchased from Polymun Scientific. Expression plasmids for antibody 1.79 [92] were provided by Dr. Michel Nussenzweig, The Rockefeller University, New York, USA. Antibody 1.79 was produced by expression in 293-F cells followed by purification of the antibody by protein $\mathrm{G}$ affinity chromatography and size exclusion chromatography as described [13]. T-20 [93] was purchased from Roche Pharmaceuticals.

\section{Cells and viruses}

293-T cells were obtained from the American Type Culture Collection (ATCC) and TZM-bl cells [94] from the NIH AIDS Research and Reference Reagent Program (NIH ARP). Both cell types were cultivated in DMEM containing $10 \%$ heat inactivated FCS and penicillin/ streptomycin. A3.01-CCR5 T cells were described previously [58] and were cultivated in RPMI containing 10\% FCS and penicillin/streptomycin. Jurkat T cells [95] were a gift from Dr. Stuart Neil, King's College, London, UK and were cultured in RPMI, 10\% FCS and penicillin/ streptomycin. rhTRIM5 $\alpha$-expressing TZM-bl cells were described previously [58].

All envelope genes used in this study were cloned into the expression vector pcDNA 3.1 (Invitrogen). Plasmids encoding the envelopes of strains JR-FL, SF162, NL-43, RHPA, AC10, REJO, ZM109 and ZM214 were obtained from the NIH ARP. Envelope clone SF162-P3N [70] was a gift from Dr. Cecilia Cheng-Mayer, Aaron Diamond AIDS Research Center, New York, USA. Envelope ZA110 was previously described [13]. Envelope clone CAP88 [96] was a gift from Dr. Lynn Morris, National Institute for Communicable Diseases, Johannesburg, South Africa. The panel of JR-CSF alanine point mutants was kindly provided Dr. Dennis Burton [65]. For the construction of V1V2 deleted viruses the restriction sites DraIII (upstream) and StuI (downstream) of the V1V2 were utilized to substitute the original V1V2 domain with a three amino acid linker sequence DAG as described [13,97]. The same strategy was employed to produce V1V2 swaps between envelopes SF162 and P3N. All other mutations were generated by site directed mutagenesis (QuikChange II kit, Agilent, Santa Clara, USA) according to the manufacturer instructions.

\section{Clinical specimen}

Plasma samples used for neutralization studies were obtained from 19 adult individuals with chronic HIV-1 infection (subtypes A, B, C, AE and AG, > 6 months infected) enrolled in the Zurich center of the Swiss HIV Cohort Study [98] and the Zurich Primary HIV-infection (ZPHI) study [99]. The plasma sample from patient ZA110 used in Figure 5, a participant of the ZPHI study, was collected 61 weeks before the time point at which the probed env was isolated [13].

\section{Ethics statement}

All clinical specimens were derived from adult participants enrolled in the Zurich center of the Swiss HIV Cohort Study [98] or the ZPHI study [99]. All studies were approved by the ethics committee of the University Hospital Zurich and written informed consent was obtained from all individuals.

\section{Sequencing}

All envelope sequence data are recorded based on HXB2 numbering. Sequencing of envelope genes was performed using in-house Sanger sequencing. 


\section{Preparation of HIV-1 virus stocks}

To prepare pseudovirus stocks 293-T cells were transfected with the respective viral backbones and the envelope of choice as described [100]. $48 \mathrm{~h}$ post-transfection, virus containing supernatants were harvested and infectivity was determined on TZM-bl reporter cells as described [100]. The following virus constructs were used: The GFP reporter HIV pseudotyping vector pNLGFPAM ([58]; denoted env-pv ${ }^{\text {NLGFP }}$ ) was co-transfected with env encoding plasmids to compare free virus infectivity and cell-fusion (Figures 2 and 3). The Luciferase reporter HIV pseudotyping vector pNLLuc-AM ([13]; denoted env-pv $\left.{ }^{\mathrm{NLLuc}}\right)$ was co-transfected with env encoding plasmids to probe free virus neutralization activity (Figures 5 and 8) and free virus stability and gp120/p24 content (Figure 4). The lentiviral packaging vector pCMV-dR8.91 ([101]; gift from Dr. Didier Trono, EPFL Lausanne, Switzerland) was co-transfected with an env encoding plasmid and the inGLuc reporter construct pUCHR-inGLuc $([56,62]$, kindly provided by Dr. Walther Mothes and Dr. Gisela Heidecker, see section on cell-cell transmission below for details). The obtained pseudoviruses (encoded env-pv ${ }^{\text {inGLuc }}$ ) were used for comparison of free virus and cell-cell transmission (Figures 1, 2, 3, 5, 6, 7, 8). To monitor cell-cell transmission in a T-cell to T-cell setting, we generated replication competent (rc) viruses containing the envelopes of JR-FL and ZA110 with the indicated mutations in the TN6 NL vector, a replicationcompetent viral backbone engineered from strain NL4-3 (kindly provided by Dr. M. Dittmar, Queen Mary University of London, UK) as described [102]. These env-TN6 encoding plasmids were co-transfected with the inGLuc reporter plasmid on Jurkat $\mathrm{T}$ cells (encoded env-rc $\mathrm{TN}^{\text {inGLuc }}$ ) and used in free virus and cell-cell transmission experiments (Figures 2 and 3). Infectivity of env$\mathrm{pv}^{\text {NLLuc }}$ and env-pv ${ }^{\text {NLGFP }}$ viruses on TZM-bl cells was quantified by measuring firefly luciferase activity using firefly luciferase substrate (Promega, Madison Wisconsin, USA). Infectivity of env-pv ${ }^{\text {inGLuc }}$ and env-rc TN6 ${ }^{\text {inGLuc }}$ on target cells (TZM-bl and A3.01-CCR5) was quantified by measuring Gaussia luciferase activity using the RenillaGlo Luciferase Assay System (Promega AG, Madison, USA).

\section{Comparing HIV-1 free virus infectivity and cell-cell transmission capacity}

We employed the recently described inGLuc reporter system $[56,62]$ to assess HIV cell-cell transmission. This setup employs a reporter plasmid (pUCHR-inGLuc) containing Gaussia luciferase in reverse orientation, interrupted by an intron in forward orientation. Splicing of the intron in plasmid-transfected HIV donor cells, packaging of the spliced RNA into virions followed by infection, reverse transcription and integration in a target cell leads to Gaussia luciferase reporter gene expression. Hence, no signal is induced in plasmid-transfected cells or from cell fusion ([56,62], Figure 1 and data not shown). Virus infectivity in this system is sensitive to both protease and RT inhibitors as expected for cell-cell transmission ([103] and Figure 1). To assess cell-cell transmission in absence of free virus transmission we restricted free virus infectivity by omission of DEAE-dextran (diethylaminoethyl-dextran; Amersham Biosciences, Fairfield, Connecticut, USA) in the infection media [58].

To directly compare free virus infectivity and cell-cell transmission, 293-T cells ( 2 wells of a 12-well plate per env; 100.000 293-T cells per well seeded one day before transfection) were transfected with env expression plasmid, inGLuc plasmid and the lentiviral packaging vector pCMV-dR8.91 $(0.2 \mu \mathrm{g}, 1.2 \mu \mathrm{g}$ and $0.6 \mu \mathrm{g}$ per well, respectively) using polyethyleneimine (PEI) as transfection reagent. $6 \mathrm{~h}$ post-transfection, one well for each env was processed for free virus infectivity, while the other well was used to probe cell-cell transmission.

\section{Free virus infectivity}

To obtain virus supernatant for estimating free virus infectivity, the supernatant of a transfected 12 well was aspired $6 \mathrm{~h}$ post transfection and replaced with $1 \mathrm{ml}$ fresh complete DMEM. $48 \mathrm{~h}$ post-transfection, the viruscontaining supernatant was harvested, cleared by centrifugation $\left(300 \mathrm{~g}, 3^{\prime}\right)$ and stored at $-80^{\circ} \mathrm{C}$. Subsequently free virus infectivity was determined by adding serial dilutions of virus stocks, starting with a maximal input of $100 \mu \mathrm{l}$, to TZM-bl or A3.01-CCR5 cells in 96-well plates in medium containing $10 \mu \mathrm{g} / \mathrm{ml}$ of DEAE-dextran and measuring Gaussia luciferase activity $60 \mathrm{~h}$ post-infection.

\section{Cell-cell transmission}

To measure cell-cell transmission, the supernatant from transfected 293-T cells was aspired $6 \mathrm{~h}$ post transfection and the cells were resuspended in $1 \mathrm{ml}$ fresh complete RPMI medium containing no DEAE (yielding approximately 15.000 cells per $100 \mu \mathrm{l}$ ). Subsequently, cells were re-seeded in 96-well plates (100 $\mu \mathrm{l}$ per well), and per well 50.000 A3.01-CCR5 cells were added in $100 \mu \mathrm{l}$ RPMI medium. After $60 \mathrm{~h}$ incubation at $37^{\circ} \mathrm{C}$ Gaussia luciferase production was measured to determine target cell infection.

\section{Assessing HIV-1 T-cell to T-cell transmission}

In order to probe virus transmission from $\mathrm{T}$-cells to $\mathrm{T}$ cells we seeded Jurkat T-cells in 12-well plates at 500.000 cells per well in complete RPMI medium. Cells were transfected with infectious molecular clones of HIV (TN6 NL vector encoding different env) and the inGLuc reporter plasmid ( $2 \mu \mathrm{g}$ and $0.5 \mu \mathrm{g}$ per well, respectively) using Jurkat TransIT (Mirus Bio LLC, Madison, USA) as 
transfection reagent. $6 \mathrm{~h}$ post-transfection, the transfection medium was removed and we either (i) added $1 \mathrm{ml}$ fresh complete RPMI, or (ii) resuspended cells in $1 \mathrm{ml}$ RPMI, transferred $100 \mu \mathrm{l}$ to 96-well plates, and added 50.000 A3.01 cells in $100 \mu \mathrm{l}$ fresh complete RPMI. From the wells containing only Jurkat cells, the cell-free supernatant was harvested $48 \mathrm{~h}$ after the medium change and the free virus titer was determined on TZM-bl cells by Gaussia luciferase read-out as described above. From the wells containing the co-culture of Jurkat and A3.01 cells, a Gaussia luciferase read-out was performed $60 \mathrm{~h}$ after starting the co-culture.

\section{Comparing HIV-1 free virus infectivity and cell-cell fusion capacity}

Free virus infectivity and cell-cell fusion activity was probed using 293-T cells producing env pseudotyped reporter virus (env-pv ${ }^{\text {NLGFP }}$ ) on TZM-bl target cells. 293-T cells were seeded in 12-well plates 1 day before transfection (100.000 cells per well in $1 \mathrm{ml}$ complete DMEM). For each env, two wells of 293-T cells were transfected with env-encoding plasmid and reporter vector pNLGFP-AM (0.5 $\mu \mathrm{g}$ plus $1.5 \mu \mathrm{g}$ per well, respectively) using PEI as transfection reagent. $6 \mathrm{~h}$ post-transfection, one well for each env was processed for free virus infectivity, while the other well was used to probe cell-cell fusion.

\section{Free virus infectivity}

For free virus infectivity, the transfection supernatant was aspired $6 \mathrm{~h}$ post transfection and replaced with $1 \mathrm{ml}$ fresh complete DMEM. $48 \mathrm{~h}$ post-transfection, the viruscontaining supernatant was harvested, cleared by centrifugation (300 g, 3') and TZM-bl cells were infected with serial dilutions of the virus supernatant in medium containing DEAE-dextran. $48 \mathrm{~h}$ post infection firefly luciferase activity in the TZM-bl cells was measured.

\section{Cell-cell fusion}

Envelope fusogenicity was assessed by Tat driven induction of firefly luciferase in TZM-bl ${ }^{\text {rh-TRIM5 } \alpha}$ targets cells upon co-culturing with 293-T cells transfected with env and the viral backbone plasmid pNLGFP-AM. In TZM$\mathrm{bl}^{\text {rh-TRIM5 } \alpha}$ cells free virus infectivity is potently restricted through expression of rhTRIM5 $\alpha$ [58,104]. Co-culturing of env pseudovirus-expressing 293-T cells with TZM$\mathrm{bl}^{\text {rh-TRIM5 } \alpha}$ cells leads to a rapid induction of the LTR driven luciferase reporter in the TZM-bl cells due to Tat transfer from transfected donor 293-T cells during fusion. To measure cell-cell fusion, the supernatant of a 12-well containing pNL-GFP AM and env transfected 293-T cells was aspired after $6 \mathrm{~h}$, and the cells were resuspended in $1 \mathrm{ml}$ fresh DMEM (yielding approximately 15.000 cells per $100 \mu \mathrm{l}$ ). Cells were then distributed in 96-well plates (100 $\mu$ l per well), and per well 15.000 TZM-bl ${ }^{\text {rh-TRIM5 } \alpha}$ cells in $100 \mu \mathrm{l}$ complete DMEM were added. After $24 \mathrm{~h}$ incubation at $37^{\circ} \mathrm{C}$ production of firefly luciferase was measured.

\section{Assessment of gp120 shedding}

To probe propensity of different envs to CD4 induced shedding of gp120 from trimers, 293-T cells were seeded in 12 -well plates $(100.000$ cells per well in $1 \mathrm{ml}$ complete DMEM). $24 \mathrm{~h}$ later, cells were transfected with envencoding plasmids and a rev-encoding plasmid (1.6 $\mu \mathrm{g}$ plus $0.4 \mu \mathrm{g}$ per well, respectively). $8 \mathrm{~h}$ post-transfection the medium was replaced, and $48 \mathrm{~h}$ post-transfection the medium was aspired and cells resuspended in FACS buffer (PBS, $2 \mathrm{mM}$ EDTA, 2\% FCS). The cells were transferred to a 96-well plate and treated with sCD4 $(10 \mu \mathrm{g} / \mathrm{ml}$ in FACS buffer) or mock (FACS buffer) for $30^{\prime}$ at $37^{\circ} \mathrm{C}$. Subsequently, the cells were washed twice with FACS buffer and envelope on the cell surface was detected with biotinylated mAb $2 \mathrm{G} 12(5 \mu \mathrm{g} / \mathrm{ml}$ in FACS buffer) and Streptavidin-APC (BioLegend, San Diego, USA; 1:400 in FACS buffer) followed by analysis of the cells on a CyAN ADP flow cytometer (Beckman Coulter, Brea, USA). Percent shedding was calculated as the mean fluorescence intensity (MFI) of the sCD4-treated cells divided by the MFI of the mock-treated cells.

\section{Quantification of gp120 and p24 content of pseudotype virus stocks}

To determine gp120 and p24 content of virus preparations, env-pv ${ }^{\text {NLLuc }}$ viruses were produced in 293-T cells (T25 flasks; 750.000 cells in $5 \mathrm{ml}$ medium, seeded $24 \mathrm{~h}$ pre-transfection). The medium was changed $12 \mathrm{~h}$ posttransfection and virus-containing supernatants harvested $48 \mathrm{~h}$ post-transfection. The supernatants were cleared by low speed centrifugation (300 g, 3'), then ultracentrifuged (SW28 rotor, $2 \mathrm{~h}, 28.000 \mathrm{rpm}, 4^{\circ} \mathrm{C}$ ), the supernatant removed and viral pellets resuspended in $0.3 \mathrm{ml}$ cold PBS and stored at $-80^{\circ} \mathrm{C}$. Virion associated p24 and gp120 antigens were quantified by ELISA as previously described [13]. Briefly, virus preparations were dissolved in 1\% Empigen (Fluka Analytical, Buchs, Switzerland) and dilutions of each sample probed for gp120 and p24. Gp120 was captured on anti-gp120 D7324 (Aalto Bioreagents, Dublin, Ireland) coated immunosorbent plates and detected with biotinylated CD4-IgG2 and Streptavidincoupled Alkaline Phosphatase (GE Healthcare, Chalfont St Giles, UK). P24 was captured on anti-gp120 D7320 (Aalto Bioreagents, Dublin, Ireland) coated plated and detected using Alkaline Phosphatase-coupled antibody BC1071-AP (Aalto Bioreagents, Dublin, Ireland).

\section{Assessment of virus temperature decay}

We employed two different experimental setups to probe temperature-induced virus infectivity loss. In the 
first assay, $250 \mu \mathrm{l}$ aliquots of wt and V1V2-deleted env-pv $v^{\text {NLLuc }}$ virus stocks were incubated at $37^{\circ} \mathrm{C}$ for up to $80 \mathrm{~h}$. At defined time points, the titer of an incubated sample was determined by titration on TZM-bL cells and set in relation to the titer of a freshly thawed aliquot to retrieve the relative loss in infectivity over time of incubation at $37^{\circ} \mathrm{C}$. For the second assay, virus stocks were transferred to 96-well PCR plates $(125 \mu \mathrm{l}$ per well) and incubated for $5 \mathrm{~h}$ over a temperature gradient ranging from $25^{\circ} \mathrm{C}$ to $45^{\circ} \mathrm{C}$ in $2.5^{\circ}$ steps in a Biometra T-gradient 96-well PCR block (Biometra GmbH, Göttingen, Germany). Following incubation, the samples were titrated on TZMbl cells and the infectivity of each sample was normalized to the sample incubated at $25^{\circ} \mathrm{C}(100 \%$ infectivity), yielding relative infectivity curves as a function of incubation temperature.

\section{Neutralization of cell-free env-pseudotyped virus}

The neutralization activity of mAbs and patient plasma against cell-free env-pv ${ }^{\text {NLLuc }}$ viruses was evaluated on TZM-bl cells as described [100]. Virus input was chosen to yield virus infectivity corresponding to a luciferase activity of 5000 to 20.000 RLU in absence of inhibitors. The antibody concentrations or reciprocal plasma titers causing 50\% reduction in viral infectivity (inhibitory concentration $\mathrm{IC}_{50}$ or neutralization titer $\mathrm{NT}_{50}$ ) were calculated by fitting pooled data from two to three independent experiments to sigmoidal dose response curves (variable slope) using GraphPad Prism. If 50\% inhibition was not achieved at the highest or lowest antibody or plasma concentration, a greater-than or less-than value was recorded.

\section{Neutralization assay during cell-cell fusion and cell-cell transmission of env-pseudotyped virus}

To assess neutralization during cell-cell fusion, 293-T cells transfected with plasmids encoding env-pv ${ }^{\text {NLGFP }}$ were re-seeded $6 \mathrm{~h}$ post transfection at 10.000 cells in $100 \mu \mathrm{l}$ DMEM medium per well of 96 well plates and serial dilutions of inhibitors ( $50 \mu \mathrm{l}$ per well) were added to the cells. Following a $1 \mathrm{~h}$ incubation at $37^{\circ} \mathrm{C}, \mathrm{TZM}-\mathrm{bl} \mathrm{r}^{\text {rhTRIM5 } \alpha}$ target cells were added to the 293-T cell - inhibitor mix (10.000 TZM-bl ${ }^{\text {rtTRIM5 } \alpha}$ cells per well in $50 \mu$ l DMEM). $24 \mathrm{~h}$ post co-culture start, firefly luciferase activity was quantified as described. To assess neutralization during cell-cell transmission, we used the same assay strategy with the following adaptations. 293-T cells were transfected with plasmids encoding env-pv ${ }^{\text {inGLuc }}$ and later co-cultured with 50.000 A3.01-CCR5 target cells per well in 96-well plates. Gaussia luciferase activity in the culture supernatant was quantified $60 \mathrm{~h}$ after co-culture. Neutralization assay data from both setups were processed in GraphPad Prism as described above for free virus neutralization.

\section{Statistical analysis}

All correlations were performed in GraphPad Prism according to Pearson. Analyses for statistical significance were performed with GraphPad Prism using either paired t-tests (Figure $4 \mathrm{~B}$ and $\mathrm{C}$, with the exact $\mathrm{p}$-values indicated) or multiple unpaired t-tests (Figures 2, 3, 6, 7) with statistical significance defined by alpha $=0.05$.

\section{Additional files}

\begin{abstract}
Additional file 1: Assay setups to study free virus infection and cell-cell transmission. (A) Overview of the assay formats used to dissect free virus infection and cell-cell transmission. (B) Experimental assay scheme: To study and quantitatively compare HIV free virus infection and cell-cell transmission virus donor cells (either 293-T cells or Jurkat T cells) were transfected with HIV encoding plasmids and the inGLuc reporter plasmid. Transfection was performed in 12-well plates, with two wells per env. Six hours post-transfection, one well was processed for cell-cell transmission, and one well for free virus infection: (i) To assess cell-cell transmission, the donor cells were resuspended in $1 \mathrm{ml}$ medium and re-seeded in $100 \mu \mathrm{l}$ volume in 96-well plates, giving approximately 15.000 293-T cells or 50.000 Jurkat cells per well. Then, 50.000 A3.01-CCR5 T-cells in $100 \mu \mathrm{l}$ medium were added and the co-culture was incubated at $37^{\circ} \mathrm{C}$ for $60 \mathrm{~h}$. To restrict free virus infection of the target cells, DEAE dextran was omitted from the culture medium. The extent of cell-cell transmission from the donor to the A3.01-CCR5 target cells was quantified by Gaussia luciferase read-out. (ii) To assess free virus infection, the virus-containing supernatant of the second 12-well of donor cells was harvested and subsequently titrated on either A3.01-CCR5 or TZM-bl target cells in 96-well plates. Assay conditions and free virus input (starting at $100 \mu \mathrm{l}$ ) were chosen to reflect cell-cell transmission co-culture conditions. The extent of free virus infectivity of the target cells was quantified by Gaussia luciferase read-out.
\end{abstract}

Additional file 2: Normalization approach for free virus infection and cell-cell transmission data. (A) In both free virus infection and cellcell transmission setups Gaussia luciferase (GLuc) activity is measured to monitor infection. Raw values are obtained as Relative Light Units (RLU). Let us assume that a wt and a mutant env have RLU values in free virus infection of $a$ and $b$, respectively. Similarly, in cell-cell transmission these envs will have RLU values of $c$ and $d$, respectively. (B) The relative infectivity of the mutant env to the wt env in free virus infection is then given by $a$ divided by $b$, multiplied by 100 to obtain the value in percent of wt infectivity. Likewise, the relative infectivity of the mutant env in cell-cell transmission is determined. (C) To obtain a measure of the relative efficacy of the mutant env in the two transmission pathways, we divide the relative cell-cell transmission activity by the relative free virus infection capacity. Thus, a value of 1 will indicate equal free virus and cell-cell transmission capacities, a value below 1 indicates better free virus infectivity than cell-cell transmission capacity, and a value greater than 1 indicates better cell-cell transmission capacity than free virus infection capacity.

Additional file 3: Gaussia luciferase activity of V1V2-deleted and wt envs in free virus infection and cell-cell transmission.

Additional file 4: Correlation analyses of V1V2-deleted env entry and trimer stability characteristics. (A) to (G): All correlations were performed in GraphPad PRISM according to Pearson. (A) Correlation analysis of $\Delta \mathrm{V} 1 \mathrm{~V} 2$ env free virus entry fitness and fusion fitness. Data are derived from Figure $3 B$ and $C$. (B) Correlation analysis of $\Delta \mathrm{V} 1 \mathrm{~V} 2$ env free virus entry fitness and virus half-life. Data are derived from Figure $3 B$ and $4 B$. (C) Correlation analysis of $\Delta \mathrm{V} 1 \mathrm{~V} 2$ env free virus entry fitness and temperature sensitivity. Data are derived from Figure 3B and 4C. (D) Correlation analysis of $\Delta$ V1V2 env fusion fitness and virus half-life. Data are derived from Figure $3 \mathrm{C}$ and $4 \mathrm{~B}$. (E) Correlation analysis of $\Delta \mathrm{V} 1 \mathrm{~V} 2$ env fusion fitness and temperature sensitivity. Data are derived from Figure $3 C$ and $4 C$. (F) Correlation analysis of $\Delta \mathrm{V} 1 \mathrm{~V} 2$ env cell-cell transmission fitness and virus half-life. Data are derived from Figure 3B and 4B. (G) Correlation analysis of $\Delta \mathrm{V} 1 \mathrm{~V} 2$ env cell-cell transmission fitness and temperature sensitivity. Data are derived from Figure $3 B$ and $4 C$. 
Additional file 5: JR-FL wt and $\Delta \mathrm{V} 1 \mathrm{~V} 2$ env expression on transfected 293-T cells and on virions. (A) Example of a flow cytometry histogram of JR-FL wt and $\Delta$ V1V2 expressing 293-T cells. Env expression on 293-T cells was detected with biotinylated mAb 2 G12 and streptavidin-APC. Mock-transfected cells subjected to the same staining protocol are shown in grey. (B) The mean fluorescence intensities (MFI) of 293-T cell populations expressing wt and V1V2-deleted envs and stained with mAb 2G12, including strains JR-FL, NL4-3 and SF162, were calculated. Mean and SD of two independent experiments are shown. (C) To derive estimates of average virion gp120 content, pseudotype virus stocks of wt and V1V2-deleted envs of the indicated strains were purified by ultracentrifugation. Subsequently, the purified virus was subjected to gp120 and p24 ELISA. Shown here are the relative gp120 and p24 contents of the V1V2-deleted strains, normalized to each matching wt strain. The p24 content of V1V2-deleted virus stocks was in the same range as the wt stocks, indicating that V1V2 deletion did not affect overall levels of pseudoparticle production. Concerning gp120 content, we observed marked reductions in gp120 content for strains ZM109 $\Delta$ V1V2 (approximately 10\% of wt gp120 content), which was not functional as free virus, and JR-FL $\Delta$ V1V2 (approximately $40 \%$ of wt gp120 content). All other strains showed gp120 levels at $\geq 80 \%$ of wt. Symbols depict mean values derived from 3 independent experiments with ELISAs performed in duplicates.

Additional file 6: Long-term incubation infectivity decay curves of wt and V1V2-deleted virions. Long-term incubation infectivity decay curves for wt virions (black) and V1V2-deleted virions (red). The data shown here were employed to calculate virus half-life as depicted in Figure 4B. Data points are mean and SD from two to three independent experiments performed in duplicates.

Additional file 7: Temperature gradient infectivity decay curves of wt and V1V2-deleted virions. Temperature gradient infectivity decay curves for wt virions (black) and V1V2-deleted virions (red). The data shown here were employed to calculate the temperature at which 50\% virus infectivity remain as depicted in Figure 4C. Data points are mean and SD from two to three independent experiments performed in duplicates.

\section{Additional file 8: Correlation analysis of virus half-life and} temperature tolerance. Correlation analyses (according to Pearson) between virus half-life (Figure 4B and Additional file 6) and temperature tolerance (Figure $4 \mathrm{C}$ and Additional file 7 ) are shown for wt virions (top) and V1V2-deleted virions (bottom)

Additional file 9: Correlation and cell-cell fusion analysis of the JR-CSF env mutant panel. (A) Correlation analysis (according to Pearson) of the data shown in Figure 6. Mutants with high discrepancy between free virus infection and cell-cell transmission capacities are marked in red. (B) Correlation analysis upon exclusion of mutants marked red in (A). (C) Comparison of free virus infectivity (black) and cell-cell fusion capacity (green) of the JR-CSF mutant panel. Fusion activity followed the same trend as seen for cell-cell transmission (Figure 6) with several mutants losing free virus infection potential but retaining cell-cell fusion capacity. Values of relative efficacy of cell-cell fusion versus free virus infection are shown below the bars; a star indicates whether this difference is statistically significant as probed by multiple unpaired t-tests with alpha $=0.05$. Data shown are mean and SD from 3 independent experiments performed in duplicates.

\section{Additional file 10: Cell-cell fusion analysis of the env N160K/K160N} mutant panel. Analysis of free virus infectivity (black) and cell-cell fusion capacity (green) of the env N160K/K160N mutant panel. We observed similar trends as shown for free virus infection and cell-cell transmission in Figure 7. Envs with the N160K mutation lost in free virus infectivity to varying extent, while cell-cell fusion activity was largely retained. SF162 and Cap88 profited from the K160N mutation and showed enhanced free virus infectivity, while cell-cell fusion capacity was only moderately increased. Values of relative efficacy of cell-cell fusion versus free virus infection are shown below the bars; a star indicates whether this difference is statistically significant as probed by multiple unpaired t-tests with alpha $=0.05$. Data shown are mean and SD from 3 independent experiments performed in duplicates.
Additional file 11: Sequence alignment of SF162 and P3N envs. Sequences were derived from in-house sequencing of the respective env clones. The V1V2 domain is boxed in red. Residue numbering is based on SF162. In addition to sequence changes in V1V2, several additional residue changes in both gp120 and gp41 are apparent in P3N compared to the parental SF162 env.

Additional file 12: Correlation analysis of neutralization sensitivity and entry fitness of the SF162/P3N env panel. Correlation analysis (according to Pearson) of IC50s for mAbs b6 and 1.79 and the free virus entry fitness of the 8 envs of the SF162/P3N V1V2 swap and point mutant panel (neutralization and free virus entry data are shown in Figure 8) highlights considerable correlation between free virus entry capacity and neutralization resistance.

Additional file 13: A putative model for V1V2 function in free virus infection and cell-cell transmission. (A) In a situation where no neutralizing Abs (black) are present, HIV-1 efficiently infects target cells both as free virus and via cell-cell transmission. (B) If neutralizing antibodies (blue) develop that bind and neutralize the contemporaneous virus trimer, free virus infection will be neutralized. However cell-cell transmission, being more resistant to antibody neutralization, may persist at lower levels. (C) Eventually, virus escape mutations to the neutralizing antibodies will emerge. These escape mutations may be located in V1V2 (indicated as red V1V2 loops). The escape mutations may interfere with V1V2 function thereby reducing free virus entry capacity (dashed arrow to target cell). However, the mutations may be better tolerated in the context of cell-cell transmission, resulting in preferential virus spread via this transmission pathway (bottom). (D) After some rounds of virus replication via cell-cell transmission, mutations in gp120/gp41 may emerge (indicated in yellow) which compensate the defects in V1V2, thereby restoring trimer functionality and free virus infectivity while maintaining antibody resistance.

\section{Competing interests}

The authors declare that they have no competing interests.

\section{Authors' contribution}

OFB and AT conceived and designed the study. OFB, PR and JW performed experiments and analyzed data. CM and RRR contributed to statistical analyses. JB contributed to envelope sequencing. HFG provided patient samples. OFB and AT wrote the manuscript. All authors read and approved the final manuscript.

\section{Acknowledgements}

We thank the patients for participating in the Swiss HIV Cohort Study and the Zurich Primary HIV Infection Study, the study nurses and physicians for excellent patient care and the datacenter for high quality data management. We thank Cyril Shah for support with sequencing. Financial support was provided by the Swiss National Science Foundation (http://www.snf.ch, grant 310000-120739 to AT) and funds from the Clinical Priority Research Program of the University of Zurich to AT and HFG.

\section{Author details}

${ }^{1}$ Institute of Medical Virology, University of Zurich, Zurich, Switzerland. ${ }^{2}$ University Hospital Zurich, Division of Infectious Diseases, Zurich, Switzerland. ${ }^{3}$ Institute of Integrative Biology, ETH Zurich, Zurich, Switzerland.

Received: 18 June 2014 Accepted: 13 August 2014 Published online: 25 September 2014

\section{References}

1. Klasse PJ: The molecular basis of HIV entry. Cell Microbiol 2012, 14:1183-1192.

2. Zwick MB, Burton DR: HIV-1 neutralization: mechanisms and relevance to vaccine design. Curr HIV Res 2007, 5:608-624.

3. Cao J, Sullivan N, Desjardin E, Parolin C, Robinson J, Wyatt R, Sodroski J: Replication and neutralization of human immunodeficiency virus type 1 lacking the V1 and V2 variable loops of the gp120 envelope glycoprotein. J Virol 1997, 71:9808-9812.

4. Morikita T, Maeda Y, Fujii S, Matsushita S, Obaru K, Takatsuki K: The V1/V2 region of human immunodeficiency virus type 1 modulates the sensitivity to neutralization by soluble CD4 and cellular tropism. AIDS Res Hum Retroviruses 1997, 13:1291-1299. 
5. Stamatatos $L$, Cheng-Mayer $C$ : An envelope modification that renders a primary, neutralization-resistant clade B human immunodeficiency virus type 1 isolate highly susceptible to neutralization by sera from other clades. J Virol 1998, 72:7840-7845.

6. Losman B, Bolmstedt A, Schonning K, Bjorndal A, Westin C, Fenyo EM, Olofsson S: Protection of neutralization epitopes in the V3 loop of oligomeric human immunodeficiency virus type 1 glycoprotein 120 by $\mathrm{N}$-linked oligosaccharides in the $\mathrm{V} 1$ region. AIDS Res Hum Retroviruses 2001, 17:1067-1076

7. Pinter A, Honnen WJ, He Y, Gorny MK, Zolla-Pazner S, Kayman SC: The V1/V2 domain of gp120 is a global regulator of the sensitivity of primary human immunodeficiency virus type 1 isolates to neutralization by antibodies commonly induced upon infection. J Virol 2004, 78:5205-5215.

8. Krachmarov C, Pinter A, Honnen WJ, Gorny MK, Nyambi PN, Zolla-Pazner S, Kayman SC: Antibodies That Are Cross-Reactive for Human Immunodeficiency Virus Type 1 Clade A and Clade B V3 Domains Are Common in Patient Sera from Cameroon, but Their Neutralization Activity Is Usually Restricted by Epitope Masking. J Virol 2005, 79:780-790.

9. Saunders CJ, McCaffrey RA, Zharkikh I, Kraft Z, Malenbaum SE, Burke B, Cheng-Mayer $C$, Stamatatos $L$ : The V1, V2, and V3 regions of the human immunodeficiency virus type 1 envelope differentially affect the viral phenotype in an isolate-dependent manner. J Virol 2005, 79:9069-9080.

10. Sagar M, Wu X, Lee $S$, Overbaugh J: Human immunodeficiency virus type $1 \mathrm{~V} 1-\mathrm{V} 2$ envelope loop sequences expand and add glycosylation sites over the course of infection, and these modifications affect antibody neutralization sensitivity. J Virol 2006, 80:9586-9598.

11. Shibata J, Yoshimura K, Honda A, Koito A, Murakami T, Matsushita S: Impact of V2 mutations on escape from a potent neutralizing anti-V3 monoclonal antibody during in vitro selection of a primary human immunodeficiency virus type 1 isolate. J Virol 2007, 81:3757-3768.

12. Ching $L K$, Vlachogiannis $G$, Bosch $K A$, Stamatatos $L$ : The first hypervariable region of the gp120 Env glycoprotein defines the neutralizing susceptibility of heterologous human immunodeficiency virus type 1 isolates to neutralizing antibodies elicited by the SF162gp140 immunogen. J Virol 2008, 82:949-956.

13. Rusert P, Krarup A, Magnus C, Brandenberg OF, Weber J, Ehlert AK, Regoes RR, Gunthard HF, Trkola A: Interaction of the gp120 V1V2 loop with a neighboring gp120 unit shields the HIV envelope trimer against cross-neutralizing antibodies. J Exp Med 2011, 208:1419-1433.

14. Starcich BR, Hahn BH, Shaw GM, McNeely PD, Modrow S, Wolf H, Parks ES, Parks WP, Josephs SF, Gallo RC, Wong-Staal F: Identification and characterization of conserved and variable regions in the envelope gene of HTLV-III/LAV, the retrovirus of AIDS. Cell 1986, 45:637-648.

15. Willey RL, Rutledge RA, Dias S, Folks T, Theodore T, Buckler CE, Martin MA: Identification of conserved and divergent domains within the envelope gene of the acquired immunodeficiency syndrome retrovirus. Proc Natl Acad Sci U S A 1986, 83:5038-5042.

16. Hu G, Liu J, Taylor KA, Roux KH: Structural comparison of HIV-1 envelope spikes with and without the V1/V2 loop. J Virol 2011, 85:2741-2750.

17. Julien JP, Cupo A, Sok D, Stanfield RL, Lyumkis D, Deller MC, Klasse PJ, Burton DR, Sanders RW, Moore JP, Ward AB, Wilson IA: Crystal Structure of a Soluble Cleaved HIV-1 Envelope Trimer. Science 2013, 342:1477-83.

18. Lyumkis D, Julien JP, de Val N, Cupo A, Potter CS, Klasse PJ, Burton DR, Sanders RW, Moore JP, Carragher B, Wilson IA, Ward AB: Cryo-EM Structure of a Fully Glycosylated Soluble Cleaved HIV-1 Envelope Trimer. Science 2013, 342:1484-90.

19. Wyatt R, Sullivan N, Thali M, Repke H, Ho D, Robinson J, Posner M, Sodroski $\mathrm{J}$ : Functional and immunologic characterization of human immunodeficiency virus type 1 envelope glycoproteins containing deletions of the major variable regions. J Virol 1993, 67:4557-4565.

20. Stamatatos L, Wiskerchen M, Cheng-Mayer C: Effect of major deletions in the V1 and V2 loops of a macrophage-tropic HIV type 1 isolate on viral envelope structure, cell entry, and replication. AIDS Res Hum Retroviruses 1998, 14:1129-1139.

21. Groenink M, Fouchier RA, Broersen S, Baker CH, Koot M, van't Wout AB, Huisman HG, Miedema F, Tersmette M, Schuitemaker H: Relation of phenotype evolution of HIV-1 to envelope V2 configuration. Science 1993, 260:1513-1516.

22. Sullivan N, Thali M, Furman C, Ho DD, Sodroski J: Effect of amino acid changes in the V1/V2 region of the human immunodeficiency virus type 1 gp120 glycoprotein on subunit association, syncytium formation, and recognition by a neutralizing antibody. J Virol 1993, 67:3674-3679.
23. Koito A, Harrowe G, Levy JA, Cheng-Mayer C: Functional role of the V1/V2 region of human immunodeficiency virus type 1 envelope glycoprotein gp120 in infection of primary macrophages and soluble CD4 neutralization. J Virol 1994, 68:2253-2259.

24. Palmer C, Balfe P, Fox D, May JC, Frederiksson R, Fenyo EM, McKeating JA: Functional characterization of the V1V2 region of human immunodeficiency virus type 1. Virology 1996, 220:436-449.

25. Toohey K, Wehrly K, Nishio J, Perryman S, Chesebro B: Human immunodeficiency virus envelope $\mathrm{V} 1$ and $\mathrm{V} 2$ regions influence replication efficiency in macrophages by affecting virus spread. Virology 1995, 213:70-79.

26. Haim H, Strack B, Kassa A, Madani N, Wang L, Courter JR, Princiotto A, McGee K, Pacheco B, Seaman MS, Smith AB 3rd, Sodroski J: Contribution of Intrinsic Reactivity of the HIV-1 Envelope Glycoproteins to CD4Independent Infection and Global Inhibitor Sensitivity. PLoS Pathog 2011, 7:e1002101.

27. Kwon YD, Finzi A, Wu X, Dogo-Isonagie C, Lee LK, Moore LR, Schmidt SD, Stuckey J, Yang Y, Zhou T, Zhu J, Vicic DA, Debnath AK, Shapiro L, Bewley CA, Mascola JR, Sodroski JG, Kwong PD: Unliganded HIV-1 gp120 core structures assume the CD4-bound conformation with regulation by quaternary interactions and variable loops. Proc Natl Acad Sci U S A 2012, 109:5663-5668.

28. Harrison SC: Viral membrane fusion. Nat Struct Mol Biol 2008, 15:690-698.

29. Myszka DG, Sweet RW, Hensley P, Brigham-Burke M, Kwong PD, Hendrickson WA, Wyatt R, Sodroski J, Doyle ML: Energetics of the HIV gp120-CD4 binding reaction. Proc Natl Acad Sci U S A 2000, 97:9026-9031.

30. Rao M, Peachman KK, Kim J, Gao G, Alving CR, Michael NL, Rao VB: HIV-1 Variable Loop 2 and its Importance in HIV-1 Infection and Vaccine Development. Curr HIV Res 2013, 11:427-438.

31. Walker LM, Phogat SK, Chan-Hui PY, Wagner D, Phung P, Goss JL, Wrin T, Simek MD, Fling S, Mitcham JL, Lehrman JK, Priddy FH, Olsen OA, Frey SM, Hammond PW, Protocol G Principal Investigators, Kaminsky S, Zamb T, Moyle M, Koff WC, Poignard P, Burton DR, Principal Investigators PG, Kaminsky S, Zamb T, Moyle M, Koff WC, Poignard P, Burton DR: Broad and potent neutralizing antibodies from an African donor reveal a new HIV-1 vaccine target. Science 2009, 326:285-289.

32. Bonsignori M, Hwang KK, Chen $X$, Tsao CY, Morris L, Gray E, Marshall DJ, Crump JA, Kapiga SH, Sam NE, Sinangil F, Pancera M, Yongping Y, Zhang B, Zhu J, Kwong PD, O'Dell S, Mascola JR, Wu L, Nabel GJ, Phogat S, Seaman MS, Whitesides JF, Moody MA, Kelsoe G, Yang X, Sodroski J, Shaw GM, Montefiori DC, Kepler TB, et al: Analysis of a clonal lineage of HIV-1 envelope V2/V3 conformational epitope-specific broadly neutralizing antibodies and their inferred unmutated common ancestors. J Virol 2011, 85:9998-10009.

33. Walker LM, Huber M, Doores KJ, Falkowska E, Pejchal R, Julien JP, Wang SK, Ramos A, Chan-Hui PY, Moyle M, Mitcham JL, Hammond PW, Olsen OA, Phung P, Fling S, Wong CH, Phogat S, Wrin T, Simek MD, Principal Investigators PG, Koff WC, Wilson IA, Burton DR, Poignard P: Broad neutralization coverage of HIV by multiple highly potent antibodies. Nature 2011, 477:466-470.

34. Gorny MK, Stamatatos L, Volsky B, Revesz K, Williams C, Wang XH, Cohen S, Staudinger R, Zolla-Pazner $S$ : Identification of a new quaternary neutralizing epitope on human immunodeficiency virus type 1 virus particles. $J$ Virol 2005, 79:5232-5237.

35. Rerks-Ngarm S, Pitisuttithum P, Nitayaphan S, Kaewkungwal J, Chiu J, Paris R, Premsri N, Namwat C, de Souza M, Adams E, Benenson M, Gurunathan S, Tartaglia J, McNeil JG, Francis DP, Stablein D, Birx DL, Chunsuttiwat S, Khamboonruang C, Thongcharoen P, Robb ML, Michael NL, Kunasol P, Kim $\mathrm{JH}, \mathrm{MOPH}-\mathrm{TAVEG}$ Investigators: Vaccination with ALVAC and AIDSVAX to prevent HIV-1 infection in Thailand. N Engl J Med 2009, 361:2209-2220.

36. Haynes BF, Gilbert PB, McElrath MJ, Zolla-Pazner S, Tomaras GD, Alam SM, Evans DT, Montefiori DC, Karnasuta C, Sutthent R, Liao HX, DeVico AL, Lewis GK, Williams C, Pinter A, Fong Y, Janes H, DeCamp A, Huang Y, Rao M, Billings E, Karasavvas N, Robb ML, Ngauy V, de Souza MS, Paris R, Ferrari G, Bailer RT, Soderberg KA, Andrews C, et al: Immune-correlates analysis of an HIV-1 vaccine efficacy trial. N Engl J Med 2012, 366:1275-1286.

37. Rolland M, Edlefsen PT, Larsen BB, Tovanabutra S, Sanders-Buell E, Hertz T, de Camp AC, Carrico C, Menis S, Magaret CA, Ahmed H, Juraska M, Chen L, Konopa P, Nariya S, Stoddard JN, Wong K, Zhao H, Deng W, Maust BS, Bose M, Howell S, Bates A, Lazzaro M, O'Sullivan A, Lei E, Bradfield A, Ibitamuno G, Assawadarachai $V$, O'Connell RJ, et al: Increased HIV-1 vaccine efficacy against viruses with genetic signatures in Env V2. Nature 2012, 490:417-420. 
38. Yates NL, Liao HX, Fong Y, de Camp A, Vandergrift NA, Williams WT, Alam SM, Ferrari G, Yang ZY, Seaton KE, Berman PW, Alpert MD, Evans DT, O'Connell RJ, Francis D, Sinangil F, Lee C, Nitayaphan S, Rerks-Ngarm S, Kaewkungwal J, Pitisuttithum P, Tartaglia J, Pinter A, Zolla-Pazner S, Gilbert PB, Nabel GJ, Michael NL, Kim JH, Montefiori DC, Haynes BF, et al: VaccineInduced Env V1-V2 IgG3 Correlates with Lower HIV-1 Infection Risk and Declines Soon After Vaccination. Sci Trans/ Med 2014, 6:228ra239.

39. Chackerian B, Rudensey LM, Overbaugh J: Specific N-linked and O-linked glycosylation modifications in the envelope $\mathrm{V} 1$ domain of simian immunodeficiency virus variants that evolve in the host alter recognition by neutralizing antibodies. J Virol 1997, 71:7719-7727.

40. Fox DG, Balfe P, Palmer CP, May JC, Arnold C, McKeating JA: Length polymorphism within the second variable region of the human immunodeficiency virus type 1 envelope glycoprotein affects accessibility of the receptor binding site. J Virol 1997, 71:759-765.

41. Shioda T, Oka S, Xin X, Liu H, Harukuni R, Kurotani A, Fukushima M, Hasan MK, Shiino T, Takebe $Y$, Iwamoto A, Nagai $Y$ : In vivo sequence variability of human immunodeficiency virus type 1 envelope gp120: association of V2 extension with slow disease progression. J Virol 1997, 71:4871-4881.

42. Masciotra S, Owen SM, Rudolph D, Yang C, Wang B, Saksena N, Spira T, Dhawan S, Lal RB: Temporal relationship between V1V2 variation, macrophage replication, and coreceptor adaptation during HIV-1 disease progression. AIDS 2002, 16:1887-1898.

43. Kitrinos KM, Hoffman NG, Nelson JA, Swanstrom R: Turnover of env variable region 1 and 2 genotypes in subjects with late-stage human immunodeficiency virus type 1 infection. J Virol 2003, 77:6811-6822.

44. Harrington PR, Nelson JA, Kitrinos KM, Swanstrom R: Independent evolution of human immunodeficiency virus type 1 env V1/V2 and V4/ V5 hypervariable regions during chronic infection. J Virol 2007, 81:5413-5417.

45. Bar KJ, Tsao CY, lyer SS, Decker JM, Yang Y, Bonsignori M, Chen X, Hwang KK, Montefiori DC, Liao HX, Hraber P, Fischer W, Li H, Wang S, Sterrett S, Keele BF, Ganusov W, Perelson AS, Korber BT, Georgiev I, McLellan JS, Pavlicek JW, Gao F, Haynes BF, Hahn BH, Kwong PD, Shaw GM: Early low-titer neutralizing antibodies impede HIV-1 replication and select for virus escape. PLoS Pathog 2012, 8:e1002721.

46. Curlin ME, Zioni R, Hawes SE, Liu Y, Deng W, Gottlieb GS, Zhu T, Mullins ال I: HIV-1 envelope subregion length variation during disease progression. PLOS Pathog 2010, 6:e1001228.

47. Doria-Rose NA, Georgiev I, O'Dell S, Chuang GY, Staupe RP, McLellan JS, Gorman J, Pancera M, Bonsignori M, Haynes BF, Burton DR, Koff WC, Kwong PD, Mascola JR: A Short Segment of the HIV-1 gp120 V1/V2 Region Is a Major Determinant of Resistance to V1/V2 Neutralizing Antibodies. J Virol 2012, 86:8319-8323.

48. Moore PL, Sheward D, Nonyane M, Ranchobe N, Hermanus T, Gray ES, Abdool Karim SS, Williamson C, Morris L: Multiple pathways of escape from HIV broadly cross-neutralizing V2-dependent antibodies. J Virol 2013, 87:4882-4894.

49. Chen $\mathrm{P}$, Hubner W, Spinelli MA, Chen BK: Predominant mode of human immunodeficiency virus transfer between T cells is mediated by sustained Env-dependent neutralization-resistant virological synapses. J Virol 2007, 81:12582-12595.

50. Sourisseau M, Sol-Foulon N, Porrot F, Blanchet F, Schwartz O: Inefficient human immunodeficiency virus replication in mobile lymphocytes. J Virol 2007, 81:1000-1012.

51. Sattentau Q: Avoiding the void: cell-to-cell spread of human viruses. Nat Rev Microbiol 2008, 6:815-826.

52. Duncan CJ, Williams JP, Schiffner T, Gartner K, Ochsenbauer C, Kappes J, Russell RA, Frater J, Sattentau QJ: High-multiplicity HIV-1 infection and neutralizing antibody evasion mediated by the macrophage-T cell virological synapse. J Virol 2014, 88:2025-2034.

53. Russell RA, Martin N, Mitar I, Jones E, Sattentau QJ: Multiple proviral integration events after virological synapse-mediated HIV-1 spread. Virology 2013, 443:143-149.

54. Del Portillo A, Tripodi J, Najfeld V, Wodarz D, Levy DN, Chen BK: Multiploid inheritance of HIV-1 during cell-to-cell infection. J Virol 2011, 85:7169-7176

55. Zhong P, Agosto LM, Munro JB, Mothes W: Cell-to-cell transmission of viruses. Curr Opin Virol 2012, 3:44-50.

56. Zhong P, Agosto LM, Ilinskaya A, Dorjbal B, Truong R, Derse D, Uchil PD, Heidecker G, Mothes W: Cell-to-cell transmission can overcome multiple donor and target cell barriers imposed on cell-free HIV. PLOS One 2013, 8:e53138.

57. Sigal A, Kim JT, Balazs AB, Dekel E, Mayo A, Milo R, Baltimore D: Cell-to-cell spread of HIV permits ongoing replication despite antiretroviral therapy. Nature 2011, 477:95-98.

58. Abela IA, Berlinger L, Schanz M, Reynell L, Gunthard HF, Rusert P, Trkola A: Cell-cell transmission enables HIV-1 to evade inhibition by potent CD4bs directed antibodies. PLOS Pathog 2012, 8:e1002634.

59. Malbec M, Porrot F, Rua R, Horwitz J, Klein F, Halper-Stromberg A, Scheid JF, Eden C, Mouquet H, Nussenzweig MC, Schwartz O: Broadly neutralizing antibodies that inhibit HIV-1 cell to cell transmission. J Exp Med 2013, 210:2813-21.

60. Jolly C, Kashefi K, Hollinshead M, Sattentau QJ: HIV-1 cell to cell transfer across an Env-induced, actin-dependent synapse. J Exp Med 2004, 199:283-293.

61. O'Rourke SM, Schweighardt B, Phung P, Fonseca DP, Terry K, Wrin T, Sinangil F, Berman PW: Mutation at a single position in the V2 domain of the HIV-1 envelope protein confers neutralization sensitivity to a highly neutralization-resistant virus. J Viro/ 2010, 84:11200-11209.

62. Mazurov D, llinskaya A, Heidecker G, Lloyd P, Derse D: Quantitative comparison of HTLV-1 and HIV-1 cell-to-cell infection with new replication dependent vectors. PLoS Pathog 2010, 6:e1000788.

63. Dale BM, Alvarez RA, Chen BK: Mechanisms of enhanced HIV spread through T-cell virological synapses. Immunol Rev 2013, 251:113-124.

64. Schiffner T, Sattentau QJ, Duncan CJ: Cell-to-cell spread of HIV-1 and evasion of neutralizing antibodies. Vaccine 2013, 31:5789-5797.

65. Pantophlet R, Ollmann Saphire E, Poignard P, Parren PW, Wilson IA, Burton DR: Fine mapping of the interaction of neutralizing and nonneutralizing monoclonal antibodies with the CD4 binding site of human immunodeficiency virus type $1 \mathrm{gp} 120$. J Virol 2003, 77:642-658.

66. Moore PL, Gray ES, Sheward D, Madiga M, Ranchobe N, Lai Z, Honnen WJ, Nonyane M, Tumba N, Hermanus T, Sibeko S, Mlisana K, Abdool Karim SS, Williamson C, Pinter A, Morris L, CAPRISA 002 Study: Potent and broad neutralization of HIV-1 subtype $C$ by plasma antibodies targeting a quaternary epitope including residues in the V2 loop. J Virol 2011, 85:3128-3141

67. Liao HX, Bonsignori M, Alam SM, McLellan JS, Tomaras GD, Moody MA, Kozink DM, Hwang KK, Chen X, Tsao CY, Liu P, Lu X, Parks RJ, Montefiori DC, Ferrari G, Pollara J, Rao M, Peachman KK, Santra S, Letvin NL, Karasavvas N, Yang ZY, Dai K, Pancera M, Gorman J, Wiehe K, Nicely NI, Rerks-Ngarm S, Nitayaphan S, Kaewkungwal J, et al: Vaccine Induction of Antibodies against a Structurally Heterogeneous Site of Immune Pressure within HIV-1 Envelope Protein Variable Regions 1 and 2. Immunity 2013.

68. Los Alamos HIV Database: HIV-1/SIVCPz env protein sequences curated alignment. 2011. http://www.hiv.lanl.gov/content/sequence/NEWALIGN/ align.html.

69. Wu X, Changela A, O'Dell S, Schmidt SD, Pancera M, Yang Y, Zhang B, Gorny MK, Phogat S, Robinson JE, Stamatatos L, Zolla-Pazner S, Kwong PD, Mascola JR: Immunotypes of a Quaternary Site of HIV-1 Vulnerability and Their Recognition by Antibodies. J Virol 2011, 85:4578-4585.

70. Ho SH, Tasca S, Shek L, Li A, Gettie A, Blanchard J, Boden D, Cheng-Mayer C: Coreceptor switch in R5-tropic simian/human immunodeficiency virus-infected macaques. J Virol 2007, 81:8621-8633.

71. Wibmer CK, Bhiman JN, Gray ES, Tumba N, Abdool Karim SS, Williamson C, Morris L, Moore PL: Viral escape from HIV-1 neutralizing antibodies drives increased plasma neutralization breadth through sequential recognition of multiple epitopes and immunotypes. PLOS Pathog 2013, 9:e1003738.

72. Honnen WJ, Krachmarov C, Kayman SC, Gorny MK, Zolla-Pazner S, Pinter A: Type-specific epitopes targeted by monoclonal antibodies with exceptionally potent neutralizing activities for selected strains of human immunodeficiency virus type 1 map to a common region of the V2 domain of gp120 and differ only at single positions from the clade B consensus sequence. J Virol 2007, 81:1424-1432.

73. Arthos J, Cicala C, Martinelli E, Macleod K, Van Ryk D, Wei D, Xiao Z, Veenstra TD, Conrad TP, Lempicki RA, McLaughlin S, Pascuccio M, Gopaul R, McNally J, Cruz CC, Censoplano N, Chung E, Reitano KN, Kottilil S, Goode DJ, Fauci AS: HIV-1 envelope protein binds to and signals through integrin alpha4beta7, the gut mucosal homing receptor for peripheral T cells. Nat Immunol 2008, 9:301-309.

74. Cicala C, Arthos J, Fauci AS: HIV-1 envelope, integrins and co-receptor use in mucosal transmission of HIV. J Transl Med 2011, 9(Suppl 1):S2. 
75. Parrish NF, Wilen CB, Banks LB, Iyer SS, Pfaff JM, Salazar-Gonzalez JF, Salazar MG, Decker JM, Parrish EH, Berg A, Hopper J, Hora B, Kumar A, Mahlokozera T, Yuan S, Coleman C, Vermeulen M, Ding H, Ochsenbauer C, Tilton JC, Permar SR, Kappes JC, Betts MR, Busch MP, Gao F, Montefiori D, Haynes BF, Shaw GM, Hahn BH, Doms RW: Transmitted/founder and chronic subtype C HIV-1 use CD4 and CCR5 receptors with equal efficiency and are not inhibited by blocking the integrin alpha4beta7. PLoS Pathog 2012, 8:e1002686.

76. Pauls E, Ballana E, Moncunill G, Bofill M, Clotet B, Ramo-Tello C, Este JA: Evaluation of the anti-HIV activity of natalizumab, an antibody against integrin alpha4. AIDS 2009, 23:266-268.

77. McLinden RJ, Labranche CC, Chenine AL, Polonis VR, Eller MA, Wieczorek L, Ochsenbauer C, Kappes JC, Perfetto S, Montefiori DC, Michael NL, Kim JH: Detection of HIV-1 neutralizing antibodies in a human CD4(+)/CXCR4 (+)/CCR5(+) T-lymphoblastoid cell assay system. PLoS One 2013, 8:e77756.

78. Mayr LM, Cohen S, Spurrier B, Kong XP, Zolla-Pazner S: Epitope mapping of conformational V2-specific anti-HIV human monoclonal antibodies reveals an immunodominant site in V2. PLoS One 2013, 8:e70859.

79. Spurrier B, Sampson J, Gorny MK, Zolla-Pazner S, Kong XP: Functional Implications of the Binding Mode of a Human Conformation-Dependent V2 Monoclonal Antibody against HIV. J Virol 2014, 88:4100-4112.

80. Chen BK: T cell virological synapses and HIV-1 pathogenesis. Immunol Res 2012, 54:133-139.

81. Murooka TT, Deruaz M, Marangoni F, Vrbanac VD, Seung E, von Andrian UH, Tager AM, Luster AD, Mempel TR: HIV-infected T cells are migratory vehicles for viral dissemination. Nature 2012, 490:283-287.

82. McLellan JS, Pancera M, Carrico C, Gorman J, Julien JP, Khayat R, Louder R, Pejchal R, Sastry M, Dai K, O'Dell S, Patel N, Shahzad-ul-Hussan S, Yang Y, Zhang B, Zhou T, Zhu J, Boyington JC, Chuang GY, Diwanji D, Georgiev I, Kwon YD, Lee D, Louder MK, Moquin S, Schmidt SD, Yang ZY, Bonsignori M, Crump JA, Kapiga SH, et al: Structure of HIV-1 gp120 V1/N2 domain with broadly neutralizing antibody PG9. Nature 2011, 480:336-343.

83. Bunnik EM, Euler Z, Welkers MR, Boeser-Nunnink BD, Grijsen ML, Prins JM, Schuitemaker H: Adaptation of HIV-1 envelope gp120 to humoral immunity at a population level. Nat Med 2010, 16:995-997.

84. Freed EO, Martin MA: Evidence for a functional interaction between the V1/V2 and C4 domains of human immunodeficiency virus type 1 envelope glycoprotein gp120. J Virol 1994, 68:2503-2512.

85. Wang WK, Essex M, Lee TH: Single amino acid substitution in constant region 1 or 4 of gp120 causes the phenotype of a human immunodeficiency virus type 1 variant with mutations in hypervariable regions 1 and 2 to revert. J Virol 1996, 70:607-611.

86. Carrillo A, Ratner $\mathrm{L}$ : Cooperative effects of the human immunodeficiency virus type 1 envelope variable loops $\mathrm{V} 1$ and $\mathrm{V} 3$ in mediating infectivity for T cells. J Virol 1996, 70:1310-1316.

87. Muster T, Steindl F, Purtscher M, Trkola A, Klima A, Himmler G, Ruker F, Katinger $\mathrm{H}$ : A conserved neutralizing epitope on gp41 of human immunodeficiency virus type 1. J Virol 1993, 67:6642-6647.

88. Trkola A, Purtscher M, Muster T, Ballaun C, Buchacher A, Sullivan N, Srinivasan K, Sodroski J, Moore JP, Katinger H: Human monoclonal antibody 2 G12 defines a distinctive neutralization epitope on the gp120 glycoprotein of human immunodeficiency virus type 1. J Virol 1996, 70:1100-1108

89. Roben P, Moore JP, Thali M, Sodroski J, Barbas CF 3rd, Burton DR: Recognition properties of a panel of human recombinant Fab fragments to the CD4 binding site of gp120 that show differing abilities to neutralize human immunodeficiency virus type 1. J Virol 1994 68:4821-4828

90. Thali M, Moore JP, Furman C, Charles M, Ho DD, Robinson J, Sodroski J: Characterization of conserved human immunodeficiency virus type 1 gp120 neutralization epitopes exposed upon gp120-CD4 binding. J Virol 1993, 67:3978-3988.

91. Zolla-Pazner S, Zhong P, Revesz K, Volsky B, Williams C, Nyambi P, Gorny $M K$ : The cross-clade neutralizing activity of a human monoclonal antibody is determined by the GPGR V3 motif of HIV type 1. AIDS Res Hum Retroviruses 2004, 20:1254-1258.

92. Scheid JF, Mouquet H, Feldhahn N, Seaman MS, Velinzon K, Pietzsch J, Ott RG, Anthony RM, Zebroski H, Hurley A, Phogat A, Chakrabarti B, Li Y, Connors M, Pereyra F, Walker BD, Wardemann H, Ho D, Wyatt RT, Mascola JR, Ravetch JV, Nussenzweig MC: Broad diversity of neutralizing antibodies isolated from memory B cells in HIV-infected individuals. Nature 2009, 458:636-640.
93. Wild C, Greenwell T, Matthews T: A synthetic peptide from HIV-1 gp41 is a potent inhibitor of virus-mediated cell-cell fusion. AIDS Res Hum Retroviruses 1993, 9:1051-1053.

94. Wei X, Decker JM, Liu H, Zhang Z, Arani RB, Kilby JM, Saag MS, Wu X, Shaw GM, Kappes JC: Emergence of resistant human immunodeficiency virus type 1 in patients receiving fusion inhibitor (T-20) monotherapy. Antimicrob Agents Chemother 2002, 46:1896-1905.

95. Kueck T, Neil SJ: A cytoplasmic tail determinant in HIV-1 Vpu mediates targeting of tetherin for endosomal degradation and counteracts interferon-induced restriction. PLOS Pathog 2012, 8:e1002609.

96. Moore PL, Ranchobe N, Lambson BE, Gray ES, Cave E, Abrahams MR, Bandawe G, Mlisana K, Abdool Karim SS, Williamson C, Morris L, CAPRISA 002 Study; NIAID Center for HIV/AIDS Vaccine Immunology (CHAVI): Limited neutralizing antibody specificities drive neutralization escape in early HIV-1 subtype C infection. PLoS Pathog 2009, 5:e1000598.

97. Bontjer I, Land A, Eggink D, Verkade E, Tuin K, Baldwin C, Pollakis G, Paxton WA, Braakman I, Berkhout B, Sanders RW: Optimization of human immunodeficiency virus type 1 envelope glycoproteins with V1/V2 deleted, using virus evolution. J Virol 2009, 83:368-383.

98. Schoeni-Affolter F, Ledergerber B, Rickenbach M, Rudin C, Gunthard HF, Telenti A, Furrer H, Yerly S, Francioli P: Cohort profile: the Swiss HIV Cohort study. Int J Epidemiol 2010, 39:1179-1189.

99. Rieder P, Joos B, von Wyl V, Kuster H, Grube C, Leemann C, Boni J, Yerly S, Klimkait T, Burgisser P, Weber R, Fischer M, Günthard HF, Swiss HIV Cohort Study: HIV-1 transmission after cessation of early antiretroviral therapy among men having sex with men. AIDS 2010, 24:1177-1183.

100. Rusert P, Mann A, Huber M, von Wyl V, Gunthard HF, Trkola A: Divergent effects of cell environment on HIV entry inhibitor activity. AIDS 2009, 23:1319-1327.

101. Zufferey R, Nagy D, Mandel RJ, Naldini L, Trono D: Multiply attenuated lentiviral vector achieves efficient gene delivery in vivo. Nat Biotechnol 1997, 15:871-875.

102. Manrique A, Rusert $P$, Joos B, Fischer M, Kuster H, Leemann C, Niederost B, Weber R, Stiegler G, Katinger H, Günthard HF, Trkola A: In vivo and in vitro escape from neutralizing antibodies 2G12, 2 F5, and 4E10. J Virol 2007, 81:8793-8808.

103. Agosto LM, Zhong P, Munro J, Mothes W: Highly Active Antiretroviral Therapies Are Effective against HIV-1 Cell-to-Cell Transmission. PLoS Pathog 2014, 10:e1003982.

104. Richardson MW, Carroll RG, Stremlau M, Korokhov N, Humeau LM, Silvestri G, Sodroski J, Riley JL: Mode of transmission affects the sensitivity of human immunodeficiency virus type 1 to restriction by rhesus TRIM5alpha. J Virol 2008, 82:11117-11128.

doi:10.1186/s12977-014-0075-y

Cite this article as: Brandenberg et al:: Partial rescue of V1V2 mutant infectivity by HIV-1 cell-cell transmission supports the domain's exceptional capacity for sequence variation. Retrovirology 2014 11:75.

\section{Submit your next manuscript to BioMed Central and take full advantage of:}

- Convenient online submission

- Thorough peer review

- No space constraints or color figure charges

- Immediate publication on acceptance

- Inclusion in PubMed, CAS, Scopus and Google Scholar

- Research which is freely available for redistribution 